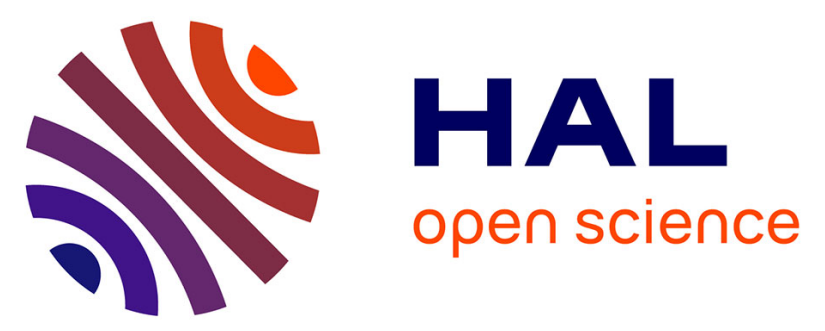

\title{
Crystallographic/experimental electron density characterizations and reactions with nucleophiles of $\beta$-enaminonitriles possessing a pyrrolobenzazepine core
}

M. Pizzonero, L. Keller, F. Dumas, M. Ourevitch, G. Morgant, Anne Spasojevic - de Biré, Goran A. Bogdanović, N.E. Ghermani, J. d’Angelo

\section{To cite this version:}

M. Pizzonero, L. Keller, F. Dumas, M. Ourevitch, G. Morgant, et al.. Crystallographic/experimental electron density characterizations and reactions with nucleophiles of $\beta$-enaminonitriles possessing a pyrrolobenzazepine core. Journal of Organic Chemistry, 2004, 69 (13), pp.4336-4350. 10.1021/jo049681x . hal-02296123

\section{HAL Id: hal-02296123 \\ https://hal.science/hal-02296123}

Submitted on 30 Sep 2020

HAL is a multi-disciplinary open access archive for the deposit and dissemination of scientific research documents, whether they are published or not. The documents may come from teaching and research institutions in France or abroad, or from public or private research centers.
L'archive ouverte pluridisciplinaire HAL, est destinée au dépôt et à la diffusion de documents scientifiques de niveau recherche, publiés ou non, émanant des établissements d'enseignement et de recherche français ou étrangers, des laboratoires publics ou privés. 


\section{Crystallographic/Experimental Electron Density Characterizations and Reactions with Nucleophiles of $\beta$-Enaminonitriles Possessing a Pyrrolobenzazepine Core}

Mathieu Pizzonero ${ }^{\S}$, Laurent Keller ${ }^{\S}$, Françoise Dumas ${ }^{\S}$, Michèle Ourevitch ${ }^{\S}$, Georges Morgant ${ }^{\S}$, Anne Spasojević-de Biré

Laboratoires BIOCIS (UMR 8076), PPB (UMR 8612), Cristallographie Bio-inorganique, Faculté de Pharmacie, Université Paris-Sud, 5, rue Jean-Baptiste Clément, 92296 Châtenay-Malabry, France and Laboratoire SPMS (UMR 8580), Ecole Centrale Paris, Grande Voie des Vignes, 92295 ChâtenayMalabry, France

jean.dangelo@cep.u-psud.fr noureddine.ghermani@cep.u-psud.fr

In connection with a total synthesis of cephalotaxine (1a), we have examined the addition of various nucleophilic reagents to $[\mathrm{ABC}]$ subunits $\mathbf{2}$ and $\mathbf{7}$ possessing a pyrrolobenzazepine core. In fact, this reaction implicates invariably the carbonyl group of 2. Regarding the reaction of 7 with nucleophiles, the most striking aspect is the complete lack of reactivity of the enaminonitrile moiety. For instance, the condensation of 7 with methylmagnesium bromide involves exclusively the cleavage of the dioxole ring, yielding regioisomers 9 and 10. With the aim of understanding the unexpected reactivity of 2 and 7 toward nucleophiles, crystallographic studies of $\mathbf{2}$ and 7, and an experimental electron density determination of 7 were carried out. The marked reactivity of the carbonyl group of 2 was interpreted by invoking the weakness of the amide resonance, due to a pronounced delocalization of the $\mathrm{N}_{9}$ lone pair over the enaminonitrile moiety. The electron density study of 7 reveals this electron delocalization along the enaminonitrile fragment, highlighted and quantified through the bond geometries, topological indicators and atomic charges, a phenomenon which is responsible for the failure of the addition of nucleophilic species.

\footnotetext{
${ }^{\S}$ BIOCIS-Université Paris-Sud

${ }^{\$}$ Laboratoire de Cristallographie-Université Paris-Sud

${ }^{\ddagger}$ SPMS-Ecole Centrale Paris

${ }^{\dagger}$ PPB-Université Paris-Sud

${ }^{£}$ Current address: Laboratory of Theoretical Physics and Condensed Matters, Institute "Vinca” P.O. Box 522, 10000 Beograd, Serbia-Montenegro
} 


\section{Introduction}

Considerable attention has been focused on a group of alkaloids produced by yew-like coniferous trees of the Cephalotaxus genus. While cephalotaxine (1a) is devoid of biological activity, ${ }^{1}$ its C-3 $\alpha-$ hydroxysuccinate esters, exemplified by homoharringtonine (1b), display highly promising antileukemic properties (Figure 1). ${ }^{2}$

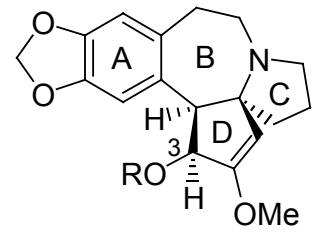

$1 \mathrm{a}: \mathrm{R}=\mathrm{H}$

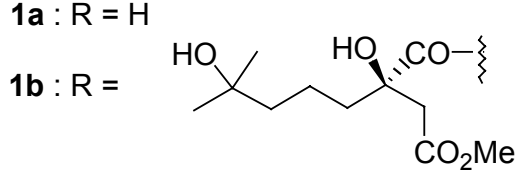

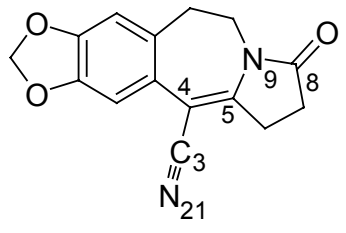

2

FIGURE 1. Structures of cephalotaxine (1a), homoharringtonine (1b) and $[\mathrm{ABC}]$ subunit 2. The cephalotaxine numbering system was used for compound 2.

In addition to potential medicinal applications, 1a has become an attractive target for the development of new synthetic methodology, because of its unique backbone architecture, consisting of a 1-azaspiro[4,4]nonane unit, fused to a benzazepine nucleus. ${ }^{3}$ Our own strategy for the synthesis of 1a has featured the use of the pyrrolobenzazepine 2 , that is readily accessible ( 7 steps, $17 \%$ overall yield) from commercially available safrole. ${ }^{4}$ The conversion of $\mathbf{2}$ into $\mathbf{1 a}$ would then require the connection of an appendage suitable for the achievement of the fourth D ring via subsequent cyclopentannulation. Although the specific tactics would depend upon the precise nature of the cyclization reaction, it appeared that this key intermediate might be accessed via either a 1,2- or 1,4-addition of an appropriate nucleophile to the conjugate nitrile moiety of 2. Prior to our own work, there existed several compelling reports showing that the reactivity of $\beta$-enaminonitriles is strongly dependent upon the degree of substitution of the amino group. The synthetic use of primary and secondary $\beta$-enaminonitriles is well documented; for example they act as nucleophilic partners in a variety of reactions with carbonyl compounds, affording nitrogen heterocycles. ${ }^{5-7}$ In comparison, tertiary $(N, N$-disubstituted $) \quad \beta$ enaminonitriles proved to be less reactive species. To date, their reactivity toward nucleophiles seems to be restricted to the intramolecular conjugate addition of dithiane anions. ${ }^{8}$ Nevertheless, ab initio calculations performed on the $\beta$-enaminonitrile system have revealed significant positive atomic charges at $\mathrm{C}_{1}$ and $\mathrm{C}_{3}$ centers of the carbon triad, ${ }^{9}$ strengthening the feasibility of 1,2-/1,4-addition of external nucleophiles, tacitly assumed in the above synthetic plan. However, since we demonstrated that the 
addition of various nucleophilic reagents to 2 implicates invariably its carbonyl function, the removal of this interfering group was undertaken. For that purpose, 2 was treated with aluminum hydride, affording 7 (Scheme 1). However, all efforts directed toward the addition of nucleophiles to the enaminonitrile moiety of 7, employing a variety of reagents and of operating conditions turned out to be unsuccessful; the only products identified during the course of this study were the dimeric structure 8 (reaction of 7 with 1-ethoxyvinyllithium) and a mixture of regioisomers $\mathbf{9}$ and $\mathbf{1 0}$ (reaction of $\mathbf{7}$ with methylmagnesium bromide) (Scheme 2). With the aim to gain further insights, which can aid in the understanding of the unexpected reactivity of $\mathbf{2}$ and 7 toward nucleophiles, crystallographic studies of 2 and 7 and an experimental electron density characterization of 7 were carried out. Results from this endeavor are reported herein.

\section{Methods : Electron Density Mapping}

Multipole Electron Density. In the Hansen-Coppens model, ${ }^{10}$ the molecular electron density is expressed as the sum of pseudo-atomic contributions given by

$$
\begin{aligned}
& \rho_{\text {at }}(\mathbf{r})=\rho_{\text {core }}(\mathrm{r})+\mathrm{P}_{\text {val }} \kappa^{3} \rho_{\text {val }}(\kappa r) \\
& +\kappa^{\prime} 3 \sum_{1=0}^{1 \max } \mathrm{R}_{1}\left(\kappa^{\prime} \mathrm{r}\right) \sum_{\mathrm{m}=0}^{1} \mathrm{P}_{\mathrm{lm} \pm} \mathrm{y}_{\mathrm{lm} \pm}(\theta, \varphi)
\end{aligned}
$$

where $\rho_{\text {core }}(r), \rho_{\text {val }}(r)$ are the frozen core and valence (normalized to one electron) spherical densities calculated from the Hartree-Fock free atom wave functions. ${ }^{11} \kappa$ is the contraction-expansion coefficient of the spherical valence electron density and $\mathrm{P}_{\mathrm{val}}$, the corresponding electron population. Therefore, the atomic charge can be estimated as the difference $\mathrm{q}=\mathrm{P}_{\mathrm{val}}-\mathrm{N}_{\mathrm{val}}$ where $\mathrm{N}_{\mathrm{val}}$ is the valence population of a free atom. The aspherical part of the pseudo-atom electron density is projected onto a real harmonics $y_{l m \pm}$ basis set $(l=0$ (monopole) to 4 (hexadecapole)) and modulated by a Slater-type radial function $R_{1}(r)=\frac{\xi^{n_{1}+3}}{\left(n_{1}+2\right) !} r^{n_{1}} e^{-\xi_{1} r}$. In equation (1), $\kappa$ ' is the contraction-expansion coefficient of the aspherical part and $\mathrm{P}_{\operatorname{lm} \pm}$ are the multipole populations of the pseudo-atom. The $\xi_{l}$ exponents ${ }^{12}$ (in bohr $^{-1}$ ) were chosen equal to $3.0,4.5,3.8$ and $\mathrm{n}_{l}=2,2,3$ up to octupole level $(l=3)$ for $\mathrm{C}, \mathrm{O}$ and $\mathrm{N}$ atoms respectively; $\xi_{l}=2.26 \mathrm{bohr}^{-1}$ and $\mathrm{n}_{l}=1$ (dipole level, $l=1$ ) for the hydrogen atoms. The MOLLY program ${ }^{10}$ was used for the refinement of the electron density of 7 extracted from the X-ray diffraction data. The static deformation electron density maps (STATDENS program ${ }^{13}$ ) were calculated in the direct space as 


$$
\Delta \rho(\mathbf{r})=\sum_{\mathrm{j}}^{\mathrm{N}}\left[\rho_{\text {model }}(\mathbf{r})-\rho_{\mathrm{HF}}(\mathbf{r})\right]_{\mathrm{j}}
$$

the difference between the pseudo-atomic (model) and Hartree-Fock (HF) free atom electron densities, respectively.

Structure and Electron Density Refinements. The WINGX software package ${ }^{14}$ was used to solve the structure and for the conventional refinements of 2 and 7 (SHELXL-97 program ${ }^{15}$ ). The experimental conditions and the statistical indices are given in Table 1. For 7, the structure refinements were carried out again with MOLLY $\operatorname{program}^{10}$ before the electron density determination. The refinement strategy is as follows. The non-hydrogen atomic coordinates and anisotropic thermal parameters were estimated by the fit to high order data $\left(\sin \theta / \lambda>0.8 \AA^{-1}\right)$. The coordinates of the hydrogen atoms and their isotropic thermal parameters were refined with all order data. The $\mathrm{C}-\mathrm{H}$ bonds were extended in order to impose the neutron diffraction distances $\mathrm{C}_{\text {aromatic }}-\mathrm{H}=1.07 \AA$ and $\mathrm{C}_{\text {ethyl }}-\mathrm{H}=$ $1.08 \AA$. All these structural parameters were relaxed in the last cycles of refinements. During the electron density refinements, the monopole and dipole parameters were constrained to be equal for the hydrogen atoms in the methylene groups. The statistical $\mathrm{R}$ factors are given in Table 1 showing that the pseudo-atomic model clearly improves the fit of the observed structure amplitudes. Figure 2 depicts the residual electron density maps of 7 (calculated as the difference $\rho_{\text {obs }}-\rho_{\text {model }}$ ) after the multipole refinements. Minima and residual peaks are in the range -0.15 to +0.10 e $\AA^{-3}$ and mainly located outside the atomic bonds. For this experiment, the estimated standard uncertainties ${ }^{16,17}$ are

$$
\begin{aligned}
& <\sigma^{2}(\Delta \rho)>^{1 / 2}=1 / \mathrm{V}\left[\sum\left(\sigma^{2}\left|\mathrm{~F}_{\text {obs }}\right|\right)\right]^{1 / 2} \\
& =0.024 \mathrm{e} \AA^{-3} \\
& <\sigma_{\text {res }}^{2}>^{1 / 2}=1 / \mathrm{V}\left[\sum\left(\left|\mathrm{F}_{\text {obs }}\right|-\left|\mathrm{F}_{\text {model }}\right|\right)^{2}\right]^{1 / 2} \\
& =0.052 \mathrm{e} \AA^{-3}
\end{aligned}
$$

where $\mathrm{F}_{\mathrm{obs}}$ and $\mathrm{F}_{\text {model }}$ are the observed and multipole model structure factor amplitudes respectively, $\sigma^{2}\left(\left|F_{\text {obs }}\right|\right)$ are the experimental variances estimated in the data processing (see Experimental Section) and $\mathrm{V}$ is the unit cell volume. The atomic numbering scheme and the ORTEP views ${ }^{18}$ of the two molecules showing 50\% probability of thermal ellipsoids obtained after the conventional refinements for 2 and after the multipole refinements for 7 are presented in Figure 3. After the multipole refinements of 7, the net atomic charges were estimated by a $\kappa$-refinement procedure ${ }^{19}$ considering the model spherical part in equation (1). 
TABLE 1. Crystallographic Experiment and Refinement Details

\begin{tabular}{|c|c|c|}
\hline & 2 & 7 \\
\hline empirical formula & $\mathrm{C}_{15} \mathrm{H}_{12} \mathrm{~N}_{2} \mathrm{O}_{3}$ & $\mathrm{C}_{15} \mathrm{H}_{14} \mathrm{~N}_{2} \mathrm{O}_{2}$ \\
\hline formula weight $\left(\mathrm{g} \cdot \mathrm{mol}^{-1}\right)$ & 268 & 254 \\
\hline temperature $(\mathrm{K})$ & $100.0(1)$ & $100.0(1)$ \\
\hline wavelength $(\AA)$ & 0.71073 & 0.71073 \\
\hline crystal system & triclinic & monoclinic \\
\hline space group & $\mathrm{P}-1$ & $\mathrm{P} 2{ }_{1} / \mathrm{n}$ \\
\hline $\mathrm{a}(\AA)$ & $7.2980(2)$ & $7.3890(1)$ \\
\hline $\mathrm{b}(\AA)$ & $9.7005(2)$ & $16.5817(1)$ \\
\hline$c(\AA)$ & $10.0029(3)$ & $9.6656(1)$ \\
\hline$\alpha\left(^{\circ}\right)$ & $111.714(1)$ & 90 \\
\hline$\beta\left(^{\circ}\right)$ & $107.052(2)$ & $97.360(1)$ \\
\hline$\gamma\left({ }^{\circ}\right)$ & $101.097(2)$ & 90 \\
\hline $\operatorname{volume}\left(\AA^{3}\right)$ & $591.77(9)$ & $1174.49(2)$ \\
\hline $\mathrm{Z}$ & 2 & 4 \\
\hline density (calculated) $\left(\mathrm{Mg} / \mathrm{m}^{3}\right)$ & 1.506 & 1.438 \\
\hline absorption coefficient $\mu\left(\left(\mathrm{mm}^{-1}\right)\right.$ & 0.107 & 0.097 \\
\hline $\mathrm{F}(000)$ & 280 & 536 \\
\hline crystal size $\left(\mathrm{mm}^{3}\right)$ & $0.55 \times 0.50 \times 0.40$ & $0.65 \times 0.54 \times 0.50$ \\
\hline color & pink & yellow-brown \\
\hline$[\sin \theta / \lambda]_{\max }\left(\AA^{-1}\right)$ & 0.78 & 1.11 \\
\hline total number of reflections & 8796 & 161121 \\
\hline unique reflections & 3747 & 13125 \\
\hline $\begin{array}{l}\mathrm{R}_{\text {int }}(\mathrm{SORTAV})^{\mathrm{a}} \\
\text { conventional refinement (SHELXL97) }\end{array}$ & 0.0413 & 0.0215 \\
\hline independent reflections $[\mathrm{I}>2 \sigma(\mathrm{I})]$ & 2542 & 10690 \\
\hline data / restraints / parameters & $3747 / 0$ / 229 & $13125 / 0 / 228$ \\
\hline $\mathrm{R}_{1}\left[\mathrm{~F}_{\mathrm{obs}}>4 \sigma\left(\mathrm{F}_{\mathrm{obs}}\right)\right]^{\mathrm{b}}$ & 0.0529 & 0.0470 \\
\hline $\mathrm{R}_{1}$ (all data) & 0.0786 & 0.0586 \\
\hline $\mathrm{wR}_{2}$ (all data) & 0.1355 & 0.1228 \\
\hline $\operatorname{gof}\left(\mathrm{F}^{2}\right)^{\mathrm{c}}$ & 0.857 & 1.093 \\
\hline $\begin{array}{l}\text { largest diff. peak and hole }\left(\mathrm{e}^{-3} \text { ) }\right. \\
\text { multipole refinement (MOLLY) }\end{array}$ & 0.52 and -0.32 & 0.82 and -0.38 \\
\hline independent reflections $[\mathrm{I}>3 \sigma(\mathrm{I})]$ & & 9842 \\
\hline $\mathrm{R}_{1}(\mathrm{~F})$ & & 0.0283 \\
\hline $\mathrm{wR}_{1}(\mathrm{~F})$ & & 0.0272 \\
\hline $\operatorname{gof}(F)^{d}$ & & 1.32 \\
\hline kappa refinement (MOLLY) & & \\
\hline independent reflections $[\mathrm{I}>3 \sigma(\mathrm{I})]$ & & 9842 \\
\hline $\mathrm{R}_{1}(\mathrm{~F})$ & & 0.0419 \\
\hline $\mathrm{wR}_{1}(\mathrm{~F})$ & & 0.0469 \\
\hline $\operatorname{gof}(\mathrm{F})^{\mathrm{d}}$ & & 2.25 \\
\hline
\end{tabular}

$a_{R_{\text {int }}}=\sum_{H}\left[\frac{N_{H}}{N_{H}-1}\right]^{\frac{1}{2}} \sum_{i=1}^{N_{H}}\left|I_{i}(H)-I_{i}^{\text {mean }}(H)\right| / \sum_{H} \sum_{i=1}^{N_{H}}\left|I_{i}(H)\right| ~ I(H)$ is the observed reflection intensity at the Bragg angle H. N(H) is the number of equivalent and redundant reflections.

$\mathrm{b}_{\mathrm{R}_{1}}=\sum\left\|\mathrm{F}_{\mathrm{obs}}|-| \mathrm{F}_{\text {calc }}\right\| / \sum\left|\mathrm{F}_{\mathrm{obs}}\right| \mathrm{wR}_{1}=\left[\sum \mathrm{w}\left(\mathrm{F}_{\mathrm{obs}}-\mathrm{F}_{\text {calc }}\right)^{2} / \sum \mathrm{wF}_{\mathrm{obs}}^{2}\right]^{\frac{1}{2}} \mathrm{R}_{2}=\sum \| \mathrm{F}_{\text {obs }}^{2}|-| \mathrm{F}_{\text {calc }}^{2}|| / \sum\left|\mathrm{F}_{\text {obs }}^{2}\right| \mathrm{wR}_{2}=\left[\sum \mathrm{w}\left(\mathrm{F}_{\mathrm{obs}}^{2}-\mathrm{F}_{\text {calc }}^{2}\right)^{2} / \sum \mathrm{wF}_{\mathrm{obs}}^{4}\right]^{\frac{1}{2}}$

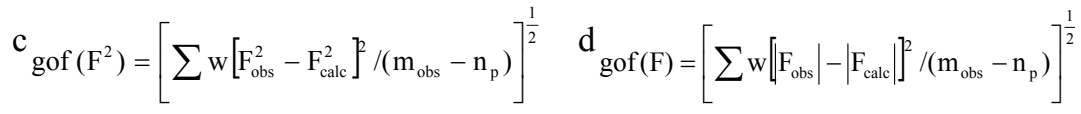

$\mathrm{F}_{\mathrm{obs}}$ and $\mathrm{F}_{\text {calc }}$ are the observed and calculated structure factors respectively. The statistical weight is $\mathrm{w}=1 / \sigma^{2}\left(\mathrm{~F}_{\mathrm{obs}}\right)$ or $1 / \sigma^{2}\left(\mathrm{~F}_{\mathrm{obs}}{ }^{2}\right)$ where $\sigma^{2}$ is the variance, $\mathrm{m}_{\mathrm{obs}}$ and $\mathrm{n}_{\mathrm{p}}$ are the number of observations and refined parameters, respectively. 

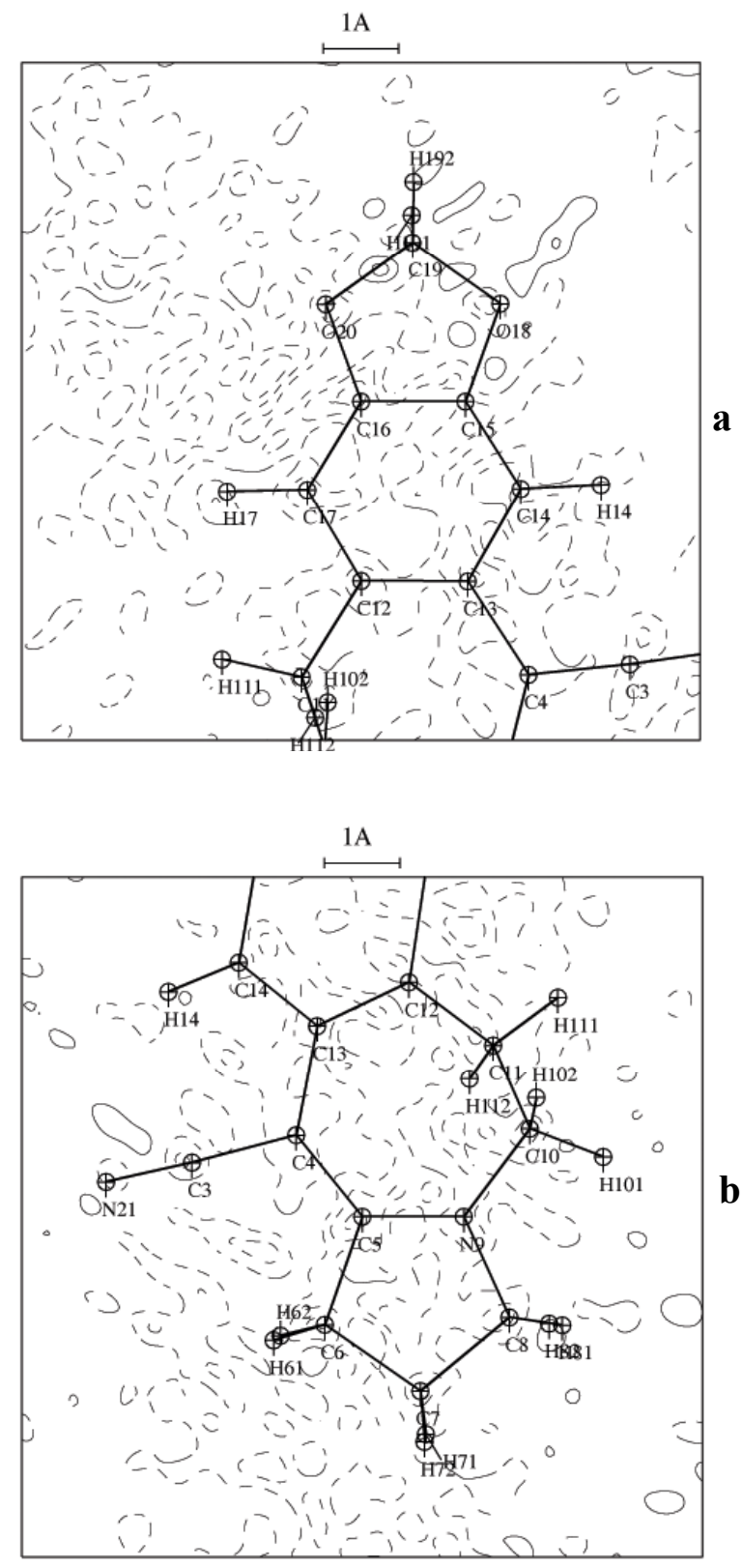

FIGURE 2. Residual electron density maps of 7. (2a) $\mathrm{O}_{19}-\mathrm{C}_{16}-\mathrm{C}_{15}$ plane; (2b) $\mathrm{C}_{4}-\mathrm{C}_{5}-\mathrm{N}_{9}$ plane. The contour interval is $0.05 \mathrm{e}^{-3}$. Negative contour lines are dashed, zero contour is omitted.

Topological Analysis of the Electron Density. The chemical bond features can be revealed by the inspection of the charge concentrations and depletions around the atoms forming the molecular system. Nowadays, the "atoms-in-molecules" (AIM) theory developed by $\mathrm{Bader}^{20}$ is largely applied for the characterization of the chemical bond in both theoretical and experimental (high-resolution X-ray diffraction results) charge density investigations. The topological analysis method is based on the particular properties of the electron density gradient $\nabla \rho(\mathbf{r})$ and Laplacian $\nabla^{2} \rho(\mathbf{r})$ around the atoms of 
the chemical system. The zeroes of the gradient localize the local extrema (critical point CP at special positions $\mathbf{r}_{\mathrm{c}}$ ) whereas the three eigenvalues (denoted $\lambda_{1}, \lambda_{2}, \lambda_{3}$ ) of the Hessian matrix at $\mathbf{r}_{\mathrm{c}}$ characterize the curvatures of the electron density. The Laplacian $\nabla^{2} \rho(\mathbf{r})$ at a position $\mathbf{r}$ in the unit cell has a physical meaning since it is directly related to the potential $v(\mathbf{r})$ (negative) and kinetic $G(\mathbf{r})$ (positive) energy densities, respectively

$$
\frac{\hbar^{2}}{4 \mathrm{~m}_{\mathrm{e}}} \nabla^{2} \rho(\mathrm{r})=2 \mathrm{G}(\mathrm{r})+\mathrm{v}(\mathrm{r})
$$

Accordingly, $\nabla^{2} \rho(\mathbf{r})<0$ corresponds to a concentration of electrons at $\mathbf{r}(v(\mathbf{r})$ dominates $)$ and $\nabla^{2} \rho(\mathbf{r})>0$ indicates a depletion $(\mathrm{G}(\mathbf{r})$ dominates) at $\mathbf{r}$. Among the different kinds of critical points, those denoted $(3,-1)$ (saddle points referred as bond critical points BCP's) for which the three eigenvalues of the Hessian matrix are non-zero and the algebraic sum of their signs is -1 , are particularly important in the bond nature characterization between interacting atoms in a molecule. The eigenvector associated with $\lambda_{3}$ is parallel to the bond path defined as the field gradient line connecting the nuclei; those associated with $\lambda_{1}$ and $\lambda_{2}$ are perpendicular to the bond path. The respective magnitudes of the eigenvalues $\lambda_{1}$ and $\lambda_{2}$ are taken into account in the bond ellipticity $\varepsilon=\left[\frac{\lambda_{1}}{\lambda_{2}}-1\right]\left(\right.$ where $\left.\left|\lambda_{1}\right| \geq\left|\lambda_{2}\right|\right)$ that reflects the shape of the electron density distribution perpendicularly to the bond path, revealing particular features like the $\pi$ bonding between atoms. The NEWPROP program ${ }^{21}$ based on the topological analysis of the experimental electron density has been used in this study.

Electrostatic Potential. The interaction energy of the molecular systems is dominated by the electrostatic part. This makes the electrostatic potential a predictive property of particular importance for the quantification of the chemical reactivity of molecules. The electrostatic potential $\mathrm{V}(\mathbf{r})$ is calculated (ELECTROS program ${ }^{13}$ ) as

$$
\mathrm{V}(\mathbf{r})=\sum_{\mathrm{j}}^{\mathrm{N}} \frac{\mathrm{Z}_{\mathrm{j}}}{\left|\mathbf{r}-\mathbf{R}_{\mathrm{j}}\right|}-\int \frac{\rho_{\text {model.j }}\left(\mathbf{r}^{\prime}\right)}{\left|\mathbf{r}-\mathbf{R}_{\mathrm{j}}-\mathbf{r}^{\prime}\right|} \mathrm{d}^{3} \mathbf{r}^{\prime}
$$

the sum of the contributions of the positive nuclear charge $Z_{j}$ and of the electron density of each pseudoatom $\mathrm{j}$ at $\mathbf{R}_{\mathrm{j}}$ with respect to the origin of the unit cell. The graphic software MOLEKEL ${ }^{22}$ has been used to visualize the electrostatic potential generated around the molecular system.

\section{Results}

Reactions of 2 and 7 with Nucleophiles. Mindful of the elaboration of our initial target 1a, we began our work with the examination of the condensation of various nucleophiles with 2 . It was our original hope to connect to the $\mathrm{C}_{5}$ center of 2 (cephalotaxine numbering) ${ }^{23}$ an acetate unit (or its 
equivalent), suitable for the elaboration of D ring of 1a, through acyloin-type cyclization. ${ }^{24}$ In our view, a particularly attractive solution to this problem involved the 1,4-addition of allylcopper reagents to the conjugate nitrile of $2 .^{25}$ However, the addition of lower order Gilman cuprates, lower order mixed cuprates or higher order mixed organocuprates, modified or not by the presence of additives $\left(\mathrm{BF}_{3}\right.$ etherate or TMSCl), ${ }^{26}$ took place exclusively on the carbonyl group, producing 3 in 53-89\% yield. An alternative route for achieving the $\mathrm{D}$ ring of $1 \mathrm{a}$ involved the 1,2-addition of 1-ethoxyvinyllithium to the nitrile group of $2,{ }^{27}$ followed by Nazarov annulation of the expected dienone. ${ }^{28}$ However, the carbonyl group of 2 was once again implicated in this condensation, resulting in the formation of 4 in $54 \%$ yield. That the carbonyl group of $\mathbf{2}$ constitutes by far its most electrophilic site was strengthened by reaction with sodium borohydride and with lithium hydroxide, leading to $\mathbf{5}$ and $\mathbf{6}$, respectively. In view of the high preference for nucleophiles to add the carbonyl function of $\mathbf{2}$, we next envisioned to remove this interfering group. While the use of conventional reducing agents $\left(\mathrm{LiAlH}_{4},{ }^{29}\right.$ DIBAL-H, ${ }^{30}$ catecholalane, ${ }^{31} \mathrm{BH}_{3}-\mathrm{Me}_{2} \mathrm{~S}$ complex ${ }^{32}$ ) was of little avail, treatment of 2 with $\mathrm{AlH}_{3}{ }^{33}$ gives the desired $\beta$ enaminonitrile 7 in $75 \%$ yield (Scheme 1).

\section{SCHEME 1. Reactions of 2 with Nucleophiles ${ }^{a}$}

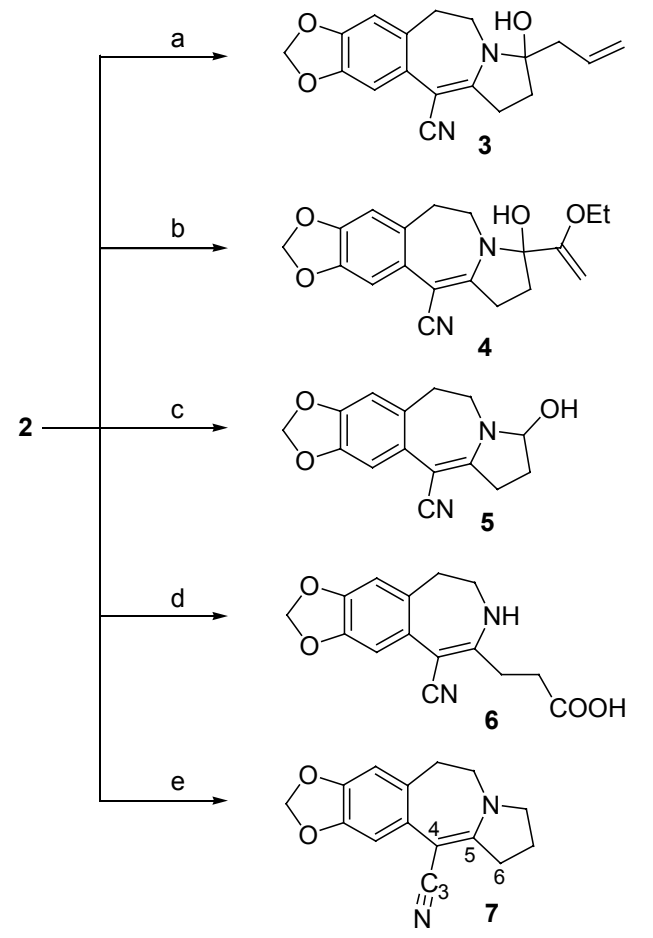

${ }^{a}$ Reagents and conditions: (a) AllylMgBr, $\mathrm{CuBr} \cdot \mathrm{Me}_{2} \mathrm{~S}$, THF, $\quad-78 \quad{ }^{\circ} \mathrm{C} ; \quad \mathrm{H}_{2} \mathrm{O}, \quad \mathrm{NH}_{4} \mathrm{Cl} \quad(89 \%)$. (b) $1-$ Ethoxyvinyllithium, THF, $-78{ }^{\circ} \mathrm{C} ; \mathrm{H}_{2} \mathrm{O}-\mathrm{MeOH}, \mathrm{NH}_{4} \mathrm{Cl}$ (54\%). (c) $\mathrm{NaBH}_{4}, \mathrm{EtOH}, 20{ }^{\circ} \mathrm{C}$ (75\%). (d) $\mathrm{LiOH}, \mathrm{H}_{2} \mathrm{O}-$ ethylene glycol, $100{ }^{\circ} \mathrm{C} ; 6 \mathrm{M} \mathrm{HCl}(69 \%)$. (e) $\mathrm{AlH}_{3}$, $\mathrm{Et}_{2} \mathrm{O}-\mathrm{THF}, 20{ }^{\circ} \mathrm{C} ; \mathrm{H}_{2} \mathrm{O}-\mathrm{NH}_{4} \mathrm{OH}(75 \%)$. 
Our efforts were then directed toward the addition of a variety of nucleophiles to 7. However, all attempts at condensing the following reagents, employing a wide range of operating conditions were uniformly unsuccessful: C-centered nucleophiles (allylcopper reagents, ${ }^{26}$ allyltrimethylsilane in the presence of TBAF, ${ }^{34}$ 1-ethoxyvinylmagnesium bromide, ${ }^{35}$ 1-ethoxyvinylcerium dichloride ${ }^{36}$ ); reducing agents $\left(\mathrm{LiAlH}_{4},(\mathrm{EtO})_{3} \mathrm{AlLiH},{ }^{37}\right.$ catecholalane, ${ }^{31}$ DIBAL-H, $\mathrm{NaBH}_{4}$ through the 1,3-benzoxathiolium tetrafluoroborate derivative, ${ }^{38} \mathrm{Et}_{3} \mathrm{SiH}$ through the $N$-ethylnitrilium tetrafluoroborate derivative, ${ }^{39}$ Raney alloy in $\left.\mathrm{AcOH}^{40}\right)$; alkali hydroxides $(\mathrm{NaOH}, \mathrm{KOH}, \mathrm{LiOH})$. In contrast, a surprising outcome was observed when 7 was subjected to 1-ethoxyvinyllithium : dimer 8 was obtained, albeit in a modest yield of $18 \%$. The meso configuration of $\mathbf{8}$ was deduced from detailed analysis of the ${ }^{1} \mathrm{H}$ and ${ }^{13} \mathrm{C} \mathrm{NMR}$ data, ${ }^{41}$ aided with 2D NMR experiments (phase-sensitive COSY, HSQC and HMBC). ${ }^{42}$ The formation of 8 can, in turn, be rationalized by invoking the self-coupling of 7 via a transient allylic anion/radical at $\mathrm{C}_{6}$ center. Another unexpected result was obtained when 7 was allowed to react with methylmagnesium bromide. When conducted at $20{ }^{\circ} \mathrm{C}$, this reaction returns only unchanged starting materials. However, under forced conditions ( $4 \mathrm{~h}$ at $110{ }^{\circ} \mathrm{C}$ ), the cleavage of the dioxole ring occurs, ${ }^{43}$ delivering in $70 \%$ combined yield a mixture of regioisomers $\mathbf{9}$ and $\mathbf{1 0}$ in the respective ratio of 2.4:1, determined by HPLC analysis of the crude. The regiochemistry of $\mathbf{9}$ and $\mathbf{1 0}$ was unequivocally assigned by ${ }^{1} \mathrm{H}$ and ${ }^{13} \mathrm{C}$ NMR spectroscopy, including COSY, HSQC and NOESY experiments. It is noteworthy that these regioisomers markedly differ in physical/spectroscopic property ( $\mathrm{mp}$, solubility, retention times in TLC and HPLC, UV spectra, IR spectra, ${ }^{1} \mathrm{H}$ and ${ }^{13} \mathrm{C}$ NMR spectra, fragmentation in mass spectroscopy), a phenomenon that parallels the remarkable regioselectivity of the reaction they are issuing (Scheme 2). 


\section{SCHEME 2. Reactions of 7 with Nucleophiles ${ }^{a}$}

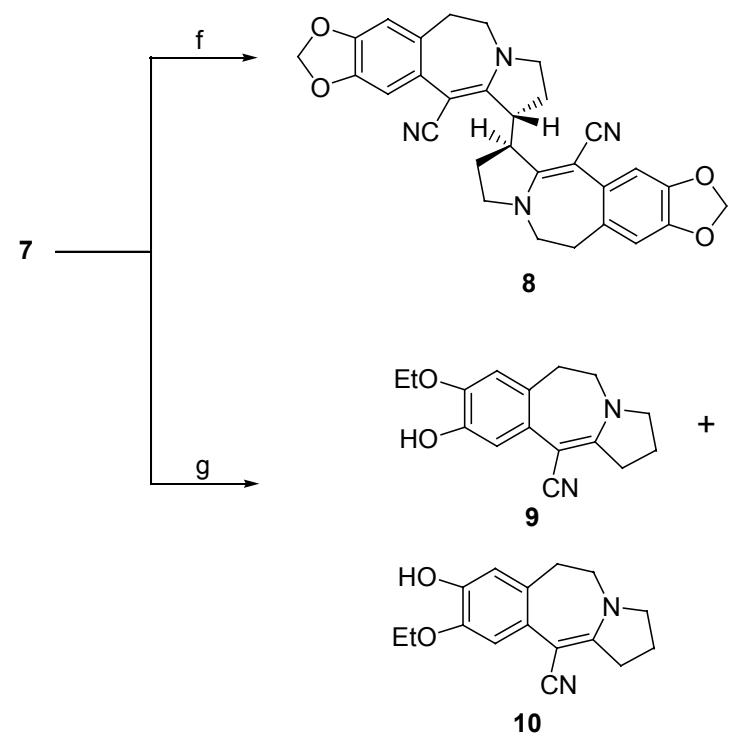

${ }^{a}$ Reagents and conditions: (f) 1-Ethoxyvinyllithium, THF, $-78{ }^{\circ} \mathrm{C}(18 \%)$. (g) $\mathrm{MeMgBr}$, toluene, $110^{\circ} \mathrm{C} ; \mathrm{H}_{2} \mathrm{O}$, $\mathrm{NH}_{4} \mathrm{Cl}(70 \%$ combined yield $; \mathbf{9} / \mathbf{1 0}$ ratio : $2.4: 1)$.

Molecular Structures and Crystal Packings of 2 and 7.2 crystallizes in the triclinic P-1 space group with two molecules in the unit cell. 7 crystallizes in the monoclinic $\mathrm{P} 2{ }_{1} / \mathrm{n}$ space group with four molecules in the unit cell. In the two crystals, the planarity of the molecules is broken at the azepine level, giving rise to two planar parts. One plane contains the pyrrolidine ring, the $\mathrm{C}_{10}$ azepine atom and the nitrile group; the second plane corresponds to that of the benzodioxole unit including the $\mathrm{C}_{11}$ atom of the azepine (Figure 3). This feature can be characterized by the torsion angle moduli defined by the $\mathrm{C}_{3^{-}}$ $\mathrm{C}_{4}-\mathrm{C}_{13}-\mathrm{C}_{12}$ fragment, which were found to be equal to $157.6(2)^{\circ}$ and $158.50(3)^{\circ}$ for 2 and 7 , respectively. Since 2 and 7 crystallize both in centrosymmetric space groups, pairs of "blocked" conformers, of opposite torsion angles, exist in each unit cell of the crystals. This clearly emphasizes that the flexibility of the two molecules rests on the $\mathrm{C}_{12}-\mathrm{C}_{11}-\mathrm{C}_{10}-\mathrm{N}_{9}$ azepine fragment. Comparatively, the $\mathrm{C}_{3}-\mathrm{C}_{4}-\mathrm{C}_{5}-\mathrm{N}_{9}$ torsion angles are equal to $179.4(2)^{\circ}$ and $179.7(1)^{\circ}$ for 2 and 7 , respectively. This implies that the five atoms $\mathrm{N}_{21}, \mathrm{C}_{3}, \mathrm{C}_{4}, \mathrm{C}_{5}$ and $\mathrm{N}_{9}$ (enaminonitrile moiety) lie very closely in the same plane. On the other hand, in the solid state, the molecules are arranged in almost parallel planes (Figures $3 \mathrm{~b}$ and $3 \mathrm{~d})$. 

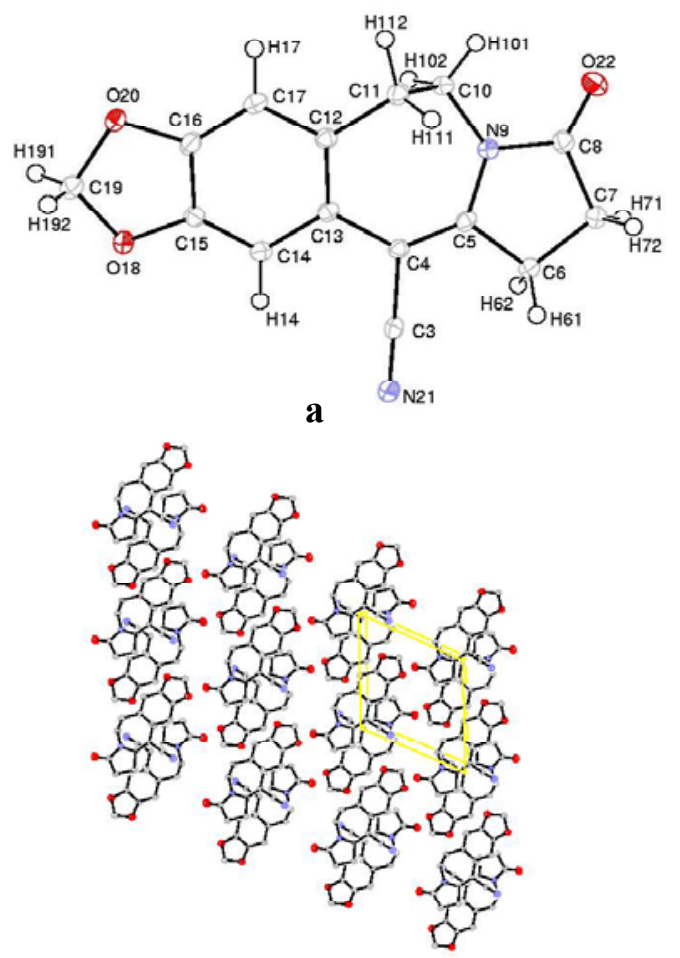

b
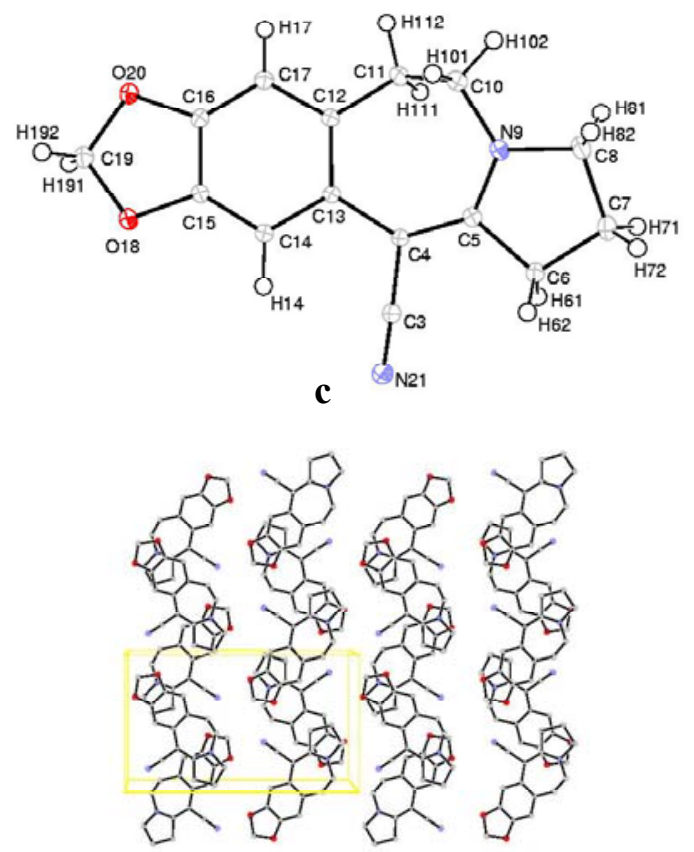

d

FIGURE 3. ORTEP views of 2 (3a) and 7 (3c) (in both cases, one conformer as been arbitrarily chosen; thermal ellipsoids at $50 \%$ probability) and the corresponding crystal stackings $(3 \mathrm{~b}, 3 \mathrm{~d})$ (a axis is perpendicular to the figure plane).

The smallest unit cell parameter $\mathrm{a}=7.2980(2) \AA$ for $\mathbf{2}$ and $\mathrm{a}=7.3890(1) \AA$ for 7 (see Table 1) corresponds to the stacking axis. The packing is, however, different in the two crystalline solids. While 
the molecules are grouped in anti-facing pairs in the crystal of 2, those of 7 form zigzag chains along the c-axis, as shown in Figure 3. Accordingly, the $\mathrm{C}_{4}-\mathrm{C}_{3}-\mathrm{N}_{21}$ moieties are anti-parallel in 2, whereas in 7 they are almost perpendicularly oriented from one molecule to another. The selected bond distances and angles obtained at the last cycle of the conventional (2) and multipole refinements (7) are reported in Table 2.

TABLE 2. Selected Bond Lengths $(\AA)$ and Angles $\left(^{\circ}\right)$ in 2 and 7

\begin{tabular}{|c|c|c|c|c|c|}
\hline \multicolumn{3}{|c|}{ bond lengths ${ }^{\mathrm{a}}$} & & \multicolumn{2}{|c|}{ angles $^{\mathrm{a}}$} \\
\hline \multicolumn{2}{|r|}{2} & 7 & & 2 & \multirow{2}{*}{$\begin{array}{c}7 \\
108.19(2)\end{array}$} \\
\hline $\mathrm{C}_{19}-\mathrm{O}_{20}$ & $1.436(2)$ & $1.4271(4)$ & $\mathrm{O}_{20}-\mathrm{C}_{19}-\mathrm{O}_{18}$ & $107.8(1)$ & \\
\hline $\mathrm{C}_{19}-\mathrm{O}_{18}$ & $1.435(2)$ & $1.4347(4)$ & $\mathrm{C}_{19}-\mathrm{O}_{20}-\mathrm{C}_{16}$ & $105.4(1)$ & $105.28(2)$ \\
\hline $\mathrm{C}_{16}-\mathrm{O}_{20}$ & $1.371(2)$ & $1.3734(3)$ & $\mathrm{C}_{19}-\mathrm{O}_{18}-\mathrm{C}_{15}$ & $105.3(1)$ & $105.48(2)$ \\
\hline $\mathrm{C}_{15}-\mathrm{O}_{18}$ & $1.379(2)$ & $1.3777(3)$ & & & \\
\hline $\mathrm{C}_{16}-\mathrm{C}_{15}$ & $1.384(3)$ & $1.3851(4)$ & & & \\
\hline $\mathrm{C}_{16}-\mathrm{C}_{17}$ & $1.373(2)$ & $1.3758(3)$ & & & \\
\hline $\mathrm{C}_{15}-\mathrm{C}_{14}$ & $1.366(2)$ & $1.3746(4)$ & & & \\
\hline $\mathrm{C}_{14}-\mathrm{C}_{13}$ & $1.423(2)$ & $1.4219(3)$ & & & \\
\hline $\mathrm{C}_{17}-\mathrm{C}_{12}$ & $1.404(2)$ & $1.4107(4)$ & & & \\
\hline $\mathrm{C}_{12}-\mathrm{C}_{13}$ & $1.405(3)$ & $1.4109(4)$ & & & \\
\hline $\mathrm{C}_{12}-\mathrm{C}_{11}$ & $1.506(2)$ & $1.5026(4)$ & $\mathrm{C}_{12}-\mathrm{C}_{11}-\mathrm{C}_{10}$ & $112.6(1)$ & $113.91(2)$ \\
\hline $\mathrm{C}_{13}-\mathrm{C}_{4}$ & $1.482(2)$ & $1.4802(4)$ & $\mathrm{C}_{13}-\mathrm{C}_{4}-\mathrm{C}_{5}$ & $131.7(2)$ & $130.18(2)$ \\
\hline $\mathrm{C}_{4}-\mathrm{C}_{3}$ & $1.444(2)$ & $1.4243(3)$ & & & \\
\hline $\mathrm{C}_{4}-\mathrm{C}_{5}$ & $1.366(2)$ & $1.3892(4)$ & & & \\
\hline $\mathrm{C}_{3}-\mathrm{N}_{21}$ & $1.150(2)$ & $1.1648(3)$ & $\mathrm{C}_{4}-\mathrm{C}_{3}-\mathrm{N}_{21}$ & $178.5(2)$ & $177.98(2)$ \\
\hline $\mathrm{C}_{10}-\mathrm{N}_{9}$ & $1.458(2)$ & $1.4551(4)$ & $\mathrm{C}_{5}-\mathrm{N}_{9}-\mathrm{C}_{8}$ & $113.0(1)$ & $114.28(2)$ \\
\hline $\mathrm{C}_{8}-\mathrm{N}_{9}$ & $1.397(2)$ & $1.4650(4)$ & $\mathrm{C}_{5}-\mathrm{N}_{9}-\mathrm{C}_{10}$ & $125.3(1)$ & $126.84(2)$ \\
\hline \multirow[t]{2}{*}{$\mathrm{C}_{5}-\mathrm{N}_{9}$} & $1.379(2)$ & $1.3418(3)$ & $\mathrm{C}_{10}-\mathrm{N}_{9}-\mathrm{C}_{8}$ & $120.8(1)$ & $118.71(2)$ \\
\hline & & & Sum & $359.1(2)$ & $359.83(3)$ \\
\hline $\mathrm{C}_{11}-\mathrm{C}_{10}$ & $1.528(2)$ & $1.5335(4)$ & & & \\
\hline $\mathrm{C}_{6}-\mathrm{C}_{5}$ & $1.516(3)$ & $1.5131(4)$ & & & \\
\hline $\mathrm{C}_{6}-\mathrm{C}_{7}$ & $1.536(2)$ & $1.5383(4)$ & $\mathrm{N}_{9}-\mathrm{C}_{8}-\mathrm{C}_{7}$ & $108.3(2)$ & $105.03(2)$ \\
\hline $\mathrm{C}_{8}-\mathrm{C}_{7}$ & $1.510(3)$ & $1.5296(5)$ & & & \\
\hline $\mathrm{C}_{8}-\mathrm{O}_{22}$ & $1.210(2)$ & & & & \\
\hline \multicolumn{6}{|c|}{ intermolecular hydrogen contacts } \\
\hline \multicolumn{3}{|c|}{2} & \multicolumn{3}{|c|}{7} \\
\hline $\mathrm{H}_{112} \cdots \mathrm{O}_{22}{ }^{\mathrm{b}}$ & $2.37(2)$ & & $\mathrm{H}_{14} \cdots \mathrm{O}_{18}{ }^{\mathrm{d}}$ & \multicolumn{2}{|l|}{$2.3920(2)$} \\
\hline \multirow[t]{3}{*}{$\mathrm{H}_{111} \cdots \mathbf{N}_{21}{ }^{\mathrm{c}}$} & \multirow[t]{3}{*}{$2.55(3)$} & & $\mathrm{H}_{112} \cdots \mathrm{O}_{20}{ }^{\mathrm{e}}$ & \multicolumn{2}{|l|}{$2.3585(3)$} \\
\hline & & & $\mathbf{H}_{62} \cdots \mathbf{O}_{20}{ }^{\mathrm{f}}$ & \multicolumn{2}{|l|}{$2.5924(3)$} \\
\hline & & & $\mathbf{H}_{81} \cdots \mathbf{N}_{21}{ }^{\mathrm{g}}$ & \multicolumn{2}{|l|}{$2.5651(3)$} \\
\hline
\end{tabular}

The different strategies adopted in the diffraction data collections (medium-resolution for 2 and highresolution for 7), combined with the conventional or multipole refinement procedures, obviously 
influence the accuracy of the results (estimated standard deviations in Table 2). However, comparisons can be made. Due to the heteroatomic nature of the connected rings forming the two kinds of molecules, the bond distances are slightly different, especially for $\mathrm{C}-\mathrm{O}$ (dioxole ring) and $\mathrm{C}-\mathrm{N}$ bonds (pyrrolidine ring and nitrile group). Indeed, $\mathrm{O}_{18}$ and $\mathrm{O}_{20}$ atoms are much closer to the phenyl nucleus ( $\mathrm{C}-\mathrm{O}=1.37 \AA$ in average) than to $\mathrm{C}_{19}(\mathrm{C}-\mathrm{O}=1.43 \AA)$. In the nitrile group, the $\mathrm{N}_{21}$ atom is engaged in a triple bond with a characteristic very short distance $\mathrm{C}_{3}-\mathrm{N}_{21}=1.150(2) \AA$ in 2 and $\mathrm{C}_{3}-\mathrm{N}_{21}=1.1648(3) \AA$ in 7. On the other hand, the lengths of the three $\mathrm{C}-\mathrm{N}$ bonds around the $\mathrm{N}_{9}$ atom of the pyrrolidine ring are markedly different ; the $\mathrm{N}_{9}-\mathrm{C}_{5}$ bond is the shorter one $\left(\mathrm{C}_{5}-\mathrm{N}_{9}=1.379(2) \AA\right.$ and 1.3418(3) $\AA$ for 2 and 7 respectively). The presence of the carbonyl group $\left(\mathrm{C}_{8}-\mathrm{O}_{22}=1.210(2) \AA\right)$ in 2 implies a significant difference with 7, highlighted in the $\mathrm{C}_{8}-\mathrm{N}_{9}$ bond length $\left(\mathrm{C}_{8}-\mathrm{N}_{9}=1.397(2)\right.$ and 1.4650(4) $\AA$ for 2 and 7, respectively) and in the $\mathrm{N}_{9}-\mathrm{C}_{8}-\mathrm{C}_{7}$ angle $\left(\mathrm{N}_{9}-\mathrm{C}_{8}-\mathrm{C}_{7}=108.3(2)^{\circ}\right.$ and $105.03(2)^{\circ}$ for $\mathbf{2}$ and 7 , respectively). However, the $\mathrm{C}_{10}-\mathrm{N}_{9}$ bond length is almost unchanged in the two molecules. Table 2 also reports the intermolecular hydrogen contacts occurring in the solid state. We select $\mathrm{H}^{\cdots} \mathrm{O}$ or $\mathrm{H}^{\cdots \cdots} \mathrm{N}$ bond distances lower than $2.6 \AA$. It should be noted that, in this bond length range, $\mathrm{O}_{18}$ and $\mathrm{O}_{20}$ atoms in $\mathbf{2}$ are not involved in any close hydrogen contacts.

Electron Deformation Density Maps of 7. The refined multipole parameters were used to generate the static electron deformation density around 7. The accumulation/depletion of the electron deformation density between atoms is not always a rigorous criterion to judge the covalency of the bonds, even for organic materials. ${ }^{44}$ In this context, the topological analysis presented below is more suitable. However, the bond polarization and lone pairs features are well reproduced in the electron deformation density maps. The static electron density projected on the two main planes of the molecule is shown in Figure 4. In the C-C bonds, the peak heights vary in the range 0.45-0.70 e $\AA^{-3}$ and the electron density is regularly distributed in the phenyl nucleus (Figure 4a). In the same plane, the dissymmetry of the $\mathrm{O}_{18}$ and $\mathrm{O}_{20}$ atoms lone pairs is clearly shown. The lowest electron deformation density peak $\left(0.15 \mathrm{e}^{-3}\right)$ is found between $\mathrm{C}_{19}$ and $\mathrm{O}_{18}$ atoms, compared to an accumulation of $0.30 \mathrm{e}^{-3}$ in the $\mathrm{C}_{19}-\mathrm{O}_{20}$ bond (Figure $4 \mathrm{a}$ ). $\mathrm{O}_{18}-\mathrm{C}_{15}$ and $\mathrm{O}_{20}-\mathrm{C}_{16}$ bonds display the same features corresponding to peak heights equal to $0.20 \mathrm{e}^{-3}$. In Figure $4 \mathrm{~b}$, the $\mathrm{C}_{3}-\mathrm{N}_{21}$ triple bond character is clearly visible through the high electron deformation density peak reaching $1.10 \mathrm{e}^{-3}$. In the same plane, the electron concentration $\left(0.60 \mathrm{e}^{-3}\right)$ in the $\mathrm{N}_{9}-\mathrm{C}_{5}$ bond is higher than in the $\mathrm{N}_{9}-\mathrm{C}_{10}$ and $\mathrm{N}_{9}-\mathrm{C}_{8}$ ones $\left(0.40 \mathrm{e} \AA^{-3}\right)$, a dissymmetry consistent with the bond distances reported in Table 2 . The particular directions of the oxygen atom lone pair polarizations are depicted in the planes of Figure 5. Such polarizations are very likely governed by intermolecular interactions in $\mathrm{O}$ ' $\mathrm{H}-\mathrm{C}$ contacts. 

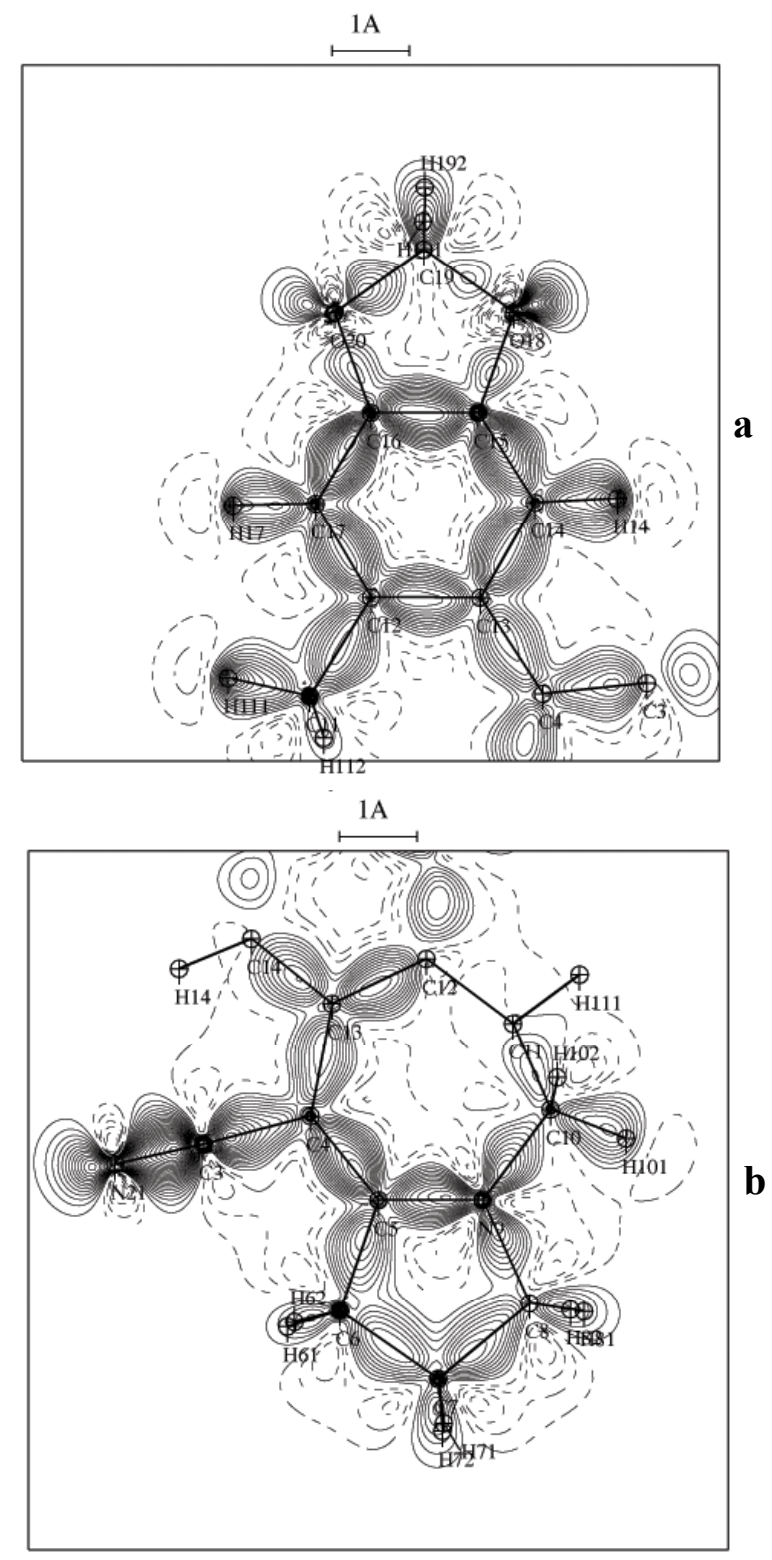

FIGURE 4. Static electron deformation density maps of 7. (4a) $\mathrm{O}_{19}-\mathrm{C}_{16}-\mathrm{C}_{15}$ plane; (4b) $\mathrm{C}_{4}-\mathrm{C}_{5}-\mathrm{N}_{9}$ plane. Contours are as in Figure 2.

Indeed, Figure 5a shows that the $\mathrm{O}_{20}$ atom is engaged in a close hydrogen contact $\mathrm{O}_{20}{ }^{\cdots} \mathrm{H}_{112}-\mathrm{C}_{11}$ $\left(\mathrm{O}_{20} \cdots \mathrm{H}_{112}=2.3585(3) \AA\right)$. However, the $\mathrm{O}_{20}$ lone pair electron density is preferentially polarized toward $\mathrm{H}_{62}$ atom involved in the longest $\mathrm{O}_{20} \cdots \mathrm{H}_{62}-\mathrm{C}_{6}$ contact $\left(\mathrm{O}_{20} \cdots \mathrm{H}_{62}=2.5924(3) \AA\right)$. These interactions occur between interlayer molecules in the crystal packing. On the other hand, the intralayer molecules are doubly connected through $\mathrm{O}_{18}{ }^{\cdots} \mathrm{H}_{14}$ contacts $\left(\mathrm{O}_{18}{ }^{\cdots} \mathrm{H}_{14}=2.3920(2) \AA\right)$. The high $\mathrm{O}_{18}$ lone pair electron density is clearly polarized toward $\mathrm{H}_{14}$ atom as shown in the plane of Figure $5 \mathrm{~b}$.

Topological Properties of the Electron Density of 7. The heteroatomicity of the connected rings forming 7 makes the topological analysis necessary in order to characterize the bond nature and the electron density repartition over the system. Table 3 reports the main topological properties derived from 
the multipole refinements. In this work, we only focused on the $(3,-1)$ saddle bond critical points (BCP's).
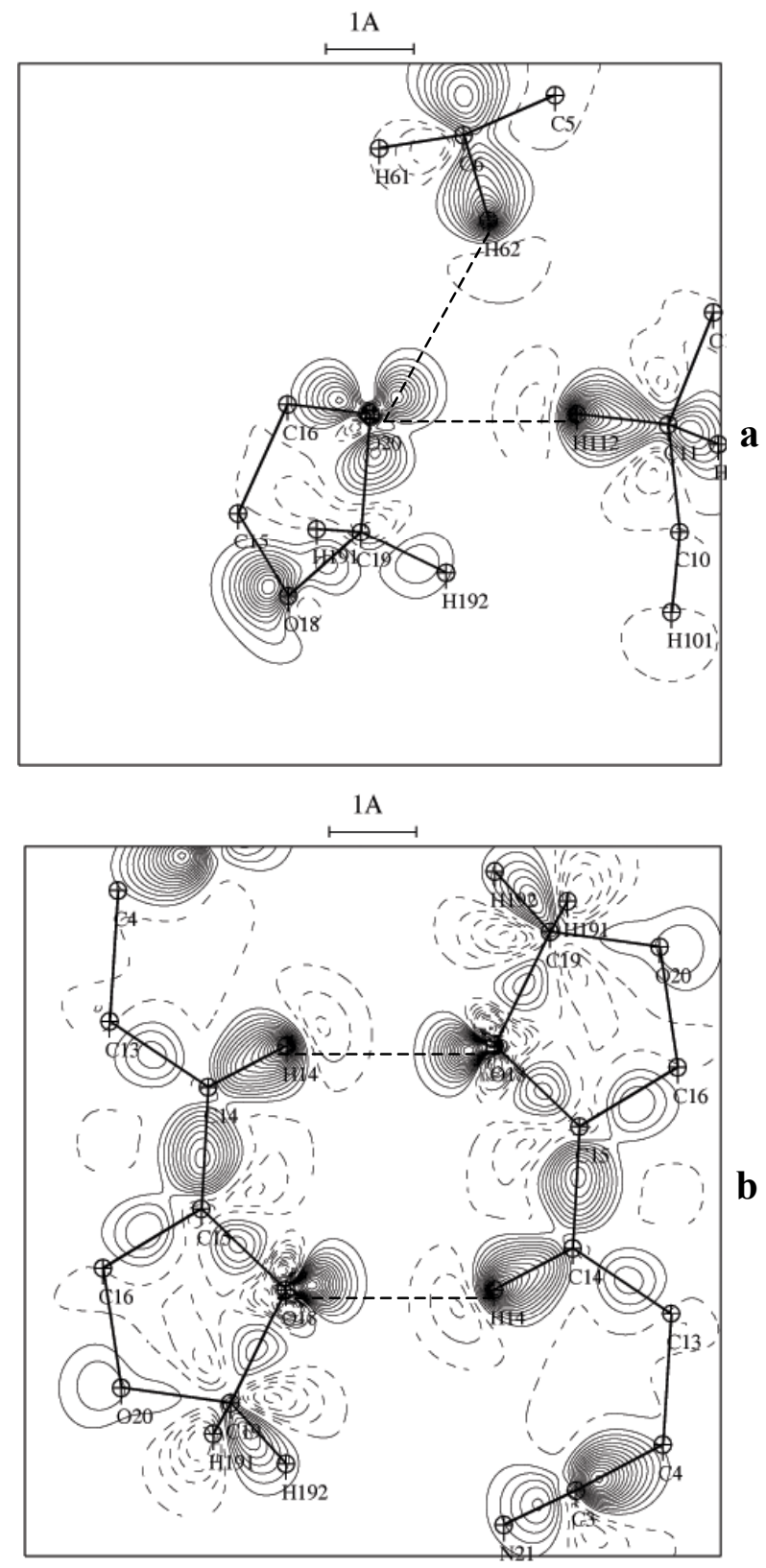

FIGURE 5. Static electron deformation density maps of 7. (5a) $\mathrm{H}_{112} \cdots \mathrm{O}_{20} \cdots \mathrm{H}_{62}$ plane; (5b) crystal double $\mathrm{H}_{14} \cdots \mathrm{O}_{18}$ intermolecular contacts. Contours are as in Figure 2.

As expected, the negativity of the Laplacian illustrates the covalent character (shared or open shell interaction) of the intramolecular atomic bonds. However, the Laplacian and the electron density magnitudes at the BCP's vary in a large domain for each type of atomic bonds: C-C, C-N, C-O and C-H. The inspection of the atom-BCP distances given in Table 3 shows that the BCP is systematically closer 
to the less electronegative atom in the case of heteroatomic links; BCP's are, in average, in the middle of the $\mathrm{C}-\mathrm{C}$ bonds (Table 3).

TABLE 3. Topological Properties at the Bond Critical Points (BCP's) of 7

\begin{tabular}{|c|c|c|c|c|c|}
\hline bond & $\mathrm{d}_{1}^{\mathrm{a}}$ & $\mathrm{d}_{2}{ }^{\mathrm{a}}$ & $\nabla^{2} \rho(\mathbf{r})^{b}$ & ${ }^{b} \rho(\mathbf{r})^{c}$ & $\varepsilon^{\mathrm{d}}$ \\
\hline $\mathrm{C}_{19}-\mathrm{O}_{20}$ & 0.587 & 0.841 & -9.68 & 1.75 & 0.16 \\
\hline $\mathrm{C}_{19}-\mathrm{O}_{18}$ & 0.613 & 0.822 & -5.13 & 1.65 & 0.27 \\
\hline $\mathrm{C}_{16}-\mathrm{O}_{20}$ & 0.575 & 0.798 & -9.21 & 1.92 & 0.10 \\
\hline $\mathrm{C}_{15}-\mathrm{O}_{18}$ & 0.584 & 0.793 & -9.29 & 1.90 & 0.17 \\
\hline$C_{15}-C_{16}$ & 0.690 & 0.695 & -19.68 & 2.19 & 0.29 \\
\hline $\mathrm{C}_{17}-\mathrm{C}_{16}$ & 0.664 & 0.712 & -19.99 & 2.18 & 0.37 \\
\hline $\mathrm{C}_{14}-\mathrm{C}_{15}$ & 0.631 & 0.744 & -18.67 & 2.15 & 0.30 \\
\hline $\mathrm{C}_{14}-\mathrm{C}_{13}$ & 0.709 & 0.713 & -15.09 & 1.99 & 0.21 \\
\hline $\mathrm{C}_{17}-\mathrm{C}_{12}$ & 0.705 & 0.706 & -15.35 & 1.96 & 0.28 \\
\hline $\mathrm{C}_{13}-\mathrm{C}_{12}$ & 0.696 & 0.715 & -15.17 & 1.97 & 0.28 \\
\hline $\mathrm{C}_{12}-\mathrm{C}_{11}$ & 0.750 & 0.753 & -11.51 & 1.70 & 0.08 \\
\hline $\mathrm{C}_{4}-\mathrm{C}_{13}$ & 0.726 & 0.755 & -10.22 & 1.66 & 0.19 \\
\hline $\mathrm{C}_{4}-\mathrm{C}_{3}$ & 0.669 & 0.756 & -10.50 & 1.82 & 0.22 \\
\hline $\mathrm{C}_{4}-\mathrm{C}_{5}$ & 0.661 & 0.728 & -16.95 & 2.05 & 0.31 \\
\hline $\mathrm{C}_{3}-\mathrm{N}_{21}$ & 0.488 & 0.676 & -32.33 & 3.42 & 0.02 \\
\hline $\mathrm{C}_{10}-\mathrm{N}_{9}$ & 0.616 & 0.839 & -8.98 & 1.73 & 0.13 \\
\hline $\mathrm{C}_{8}-\mathrm{N}_{9}$ & 0.620 & 0.846 & -6.32 & 1.63 & 0.17 \\
\hline $\mathrm{C}_{5}-\mathrm{N}_{9}$ & 0.558 & 0.785 & -19.52 & 2.29 & 0.24 \\
\hline $\mathrm{C}_{10}-\mathrm{C}_{11}$ & 0.736 & 0.798 & -9.13 & 1.58 & 0.11 \\
\hline $\mathrm{C}_{6}-\mathrm{C}_{5}$ & 0.722 & 0.791 & -9.08 & 1.59 & 0.15 \\
\hline $\mathrm{C}_{6}-\mathrm{C}_{7}$ & 0.765 & 0.773 & -8.68 & 1.57 & 0.06 \\
\hline $\mathrm{C}_{8}-\mathrm{C}_{7}$ & 0.744 & 0.786 & -9.08 & 1.60 & 0.12 \\
\hline $\mathrm{H}_{14}-\mathrm{C}_{14}$ & 0.373 & 0.692 & -16.61 & 1.82 & 0.08 \\
\hline $\mathrm{H}_{17}-\mathrm{C}_{17}$ & 0.344 & 0.723 & -16.98 & 1.73 & 0.08 \\
\hline $\mathrm{H}_{191}-\mathrm{C}_{19}$ & 0.368 & 0.717 & -13.91 & 1.74 & 0.06 \\
\hline $\mathrm{H}_{192}-\mathrm{C}_{19}$ & 0.365 & 0.718 & -15.02 & 1.78 & 0.13 \\
\hline $\mathrm{H}_{111}-\mathrm{C}_{11}$ & 0.387 & 0.697 & -14.10 & 1.71 & 0.06 \\
\hline $\mathrm{H}_{112}-\mathrm{C}_{11}$ & 0.381 & 0.703 & -14.52 & 1.74 & 0.02 \\
\hline $\mathrm{H}_{101}-\mathrm{C}_{10}$ & 0.398 & 0.686 & -14.19 & 1.72 & 0.12 \\
\hline $\mathrm{H}_{102}-\mathrm{C}_{10}$ & 0.387 & 0.696 & -14.86 & 1.78 & 0.08 \\
\hline $\mathrm{H}_{61}-\mathrm{C}_{6}$ & 0.362 & 0.722 & -13.76 & 1.72 & 0.04 \\
\hline $\mathrm{H}_{62}-\mathrm{C}_{6}$ & 0.371 & 0.712 & -12.82 & 1.66 & 0.07 \\
\hline $\mathrm{H}_{81}-\mathrm{C}_{8}$ & 0.399 & 0.684 & -13.07 & 1.70 & 0.16 \\
\hline $\mathrm{H}_{82}-\mathrm{C}_{8}$ & 0.398 & 0.687 & -11.82 & 1.68 & 0.08 \\
\hline $\mathrm{H}_{71}-\mathrm{C}_{7}$ & 0.399 & 0.685 & -12.25 & 1.69 & 0.10 \\
\hline \multirow[t]{2}{*}{$\mathrm{H}_{72}-\mathrm{C}_{7}$} & 0.400 & 0.685 & -12.46 & 1.69 & 0.08 \\
\hline & \multicolumn{5}{|c|}{$\mathrm{H}^{\cdots} \mathrm{O}$ contacts } \\
\hline $\mathrm{H}_{14} \cdots \mathrm{O}_{18}$ & 0.974 & 1.468 & 0.96 & 0.04 & 0.22 \\
\hline $\mathrm{H}_{112} \cdots \mathrm{O}_{20}$ & 0.922 & 1.454 & 1.11 & 0.04 & 0.29 \\
\hline $\mathbf{H}_{62} \cdots \mathbf{O}_{20}$ & 1.123 & 1.505 & 0.68 & 0.04 & 0.15 \\
\hline
\end{tabular}


Obviously, the highest values $\nabla^{2} \rho(\mathbf{r})=-32.33 \mathrm{e} \AA^{-5}$ and $\rho(\mathbf{r})=3.42$ e $\AA^{-3}$ were found for the $\mathrm{C}_{3}-\mathrm{N}_{21}$ bond displaying a cylindrical shape (ellipticity: $\varepsilon=0.02$ ). Comparatively, the electron concentration at the BCP is much more pronounced in the $\mathrm{C}_{5}-\mathrm{N}_{9}$ bond $\left(\rho(\mathbf{r})=2.29 \mathrm{e}^{-3}\right)$ than in the $\mathrm{C}_{10}-\mathrm{N}_{9}\left(\rho(\mathbf{r})=1.73\right.$ e $\AA^{-}$ $\left.{ }^{3}\right)$ and $\mathrm{C}_{8}-\mathrm{N}_{9}\left(\rho(\mathbf{r})=1.63 \mathrm{e} \AA^{-3}\right)$ ones. The latter also displays the smallest value of the negative Laplacian $\left(\nabla^{2} \rho(\mathbf{r})=-6.32 \mathrm{e} \AA^{-5}\right)$. On the other hand, the C-O bond topological properties show similar trends, except for the $\mathrm{C}_{19} \mathrm{O}_{18}$ link which presents the lowest $\nabla^{2} \rho(\mathbf{r})\left(-5.13 \mathrm{e} \AA^{-5}\right)$ and $\rho(\mathbf{r})\left(1.65 \mathrm{e} \AA^{-3}\right)$ (Table 3$)$. This exception is in agreement with the observation made from the static electron deformation density maps. With respect to their topological properties, the C-C bonds can be separated under two groups with significant differences in magnitudes. The first group, which contains the $\mathrm{C}-\mathrm{C}$ bonds of the phenyl nucleus and $\mathrm{C}_{4}-\mathrm{C}_{5}$ of the azepine ring, exhibits the highest magnitudes of $\nabla^{2} \rho(\mathbf{r})$ and $\rho(\mathbf{r})$, ranging from -15 to $-20 \mathrm{e} \AA^{-5}$ and from 2.0 to $2.2 \mathrm{e} \AA^{-3}$, respectively. The corresponding topological values are much smaller for the second group of C-C bonds, especially for those of the pyrrolidine ring (Table 3). $\mathrm{CH}$ and $\mathrm{CH}_{2}$ groups display consistent values of the Laplacian and the electron density at the BCP's. If the electron density is almost the same $\left(\rho(\mathbf{r})=1.7 \mathrm{e} \AA^{-3}\right.$ in average) for the two groups, the absolute value of the Laplacian is, however, higher $\left(\nabla^{2} \rho(\mathbf{r})=-16.8 \mathrm{e} \AA^{-5}\right.$ in average) for the aromatic $\mathrm{C}$-H bonds as shown in Table 3. The topological properties of $\mathrm{C}-\mathrm{H} \ldots \mathrm{O}$ intermolecular contacts are also given in this table. The electron densities at the BCP's are equal for the three contacts $\left(\rho(\mathbf{r})=0.04 \mathrm{e}^{-3}\right)$ whereas the positive (closed shell interaction) $\nabla^{2} \rho(\mathbf{r})$ varies from +0.7 to $+1.1 \mathrm{e}^{-5}$.

Atomic Charges of 7. The $\kappa$-refinement ${ }^{19}$ was carried out in order to estimate the net atomic charges for 7 . The results are given in Table 4 . The $\kappa$ values for non-hydrogen atoms are very close to 1.0 , showing that the atomic electron density is not significantly contracted $(\kappa>1)$ or expanded $(\kappa<1)$. This is not the case for the hydrogen atoms displaying expected large contraction parameters $(\kappa=1.3-$ 1.4). With respect to the different ring fragments forming 7 , the following carbon atoms carry an almost zero charge: $\mathrm{C}_{16}, \mathrm{C}_{15}, \mathrm{C}_{12}, \mathrm{C}_{13}, \mathrm{C}_{4}, \mathrm{C}_{8}$ and $\mathrm{C}_{5}$. This also holds for $\mathrm{C}_{19}$ atom of the dioxole ring and for $\mathrm{C}_{3}$ (nitrile group), owing to the proximity of electronegative atoms. The net charges of the other carbon atoms vary from $-0.22(6)$ e $\left(\mathrm{C}_{17}\right)$ to $-0.52(7)$ e $\left(\mathrm{C}_{14}\right)$. This variation yields different polarities for the $\mathrm{CH}$ and $\mathrm{CH}_{2}$ groups, since the hydrogen charges are all equal to ca. +0.3 e and +0.2 e for the aromatic and methylene protons, respectively, with the exception of $\mathrm{H}_{191}$ and $\mathrm{H}_{192}$, which turned out to be much less charged $(+0.11(4)$ e). For the nitrogen atoms, a charge of -0.43(5) e was found for the nitrile $\mathrm{N}$-atom $\left(\mathrm{N}_{21}\right)$, as expected for this particular polar group. Comparatively, $\mathrm{N}_{9}$ exhibits a much lower charge ($0.11(5) \mathrm{e})$. Concerning the aromatic part of 7 , it should be pointed out that the dissymmetry in the electronic effects caused by the azepine carbon centers in interaction with the $\pi$-electron system of the 
phenyl nucleus $\left(\mathrm{C}_{4}:-0.08(6)\right.$ e, $\mathrm{C}_{11}:-0.39(7)$ e) is at the origin of the differences in atomic charge between $\mathrm{C}_{14}\left(-0.52(7)\right.$ e) and $\mathrm{C}_{17}(-0.22(6) \mathrm{e})$, and between $\mathrm{O}_{18}\left(-0.12(4)\right.$ e) and $\mathrm{O}_{20}(-0.21(4)$ e).

TABLE 4. Atomic Net Charges and $\kappa$ Values of 7

\begin{tabular}{|c|c|c|c|c|c|c|}
\hline $\begin{array}{c}\text { atom } \\
\text { C }\end{array}$ & $\kappa^{\mathrm{a}}$ & charge $^{a, b}$ & $\begin{array}{l}\text { atom } \\
\mathbf{H}\end{array}$ & $\kappa^{\mathrm{a}}$ & charge $^{\mathrm{a}, \mathrm{b}}$ & $\mathrm{CH}$ and $\mathrm{CH}_{2}$ charges ${ }^{\mathrm{b}}$ \\
\hline \multirow[t]{2}{*}{$\mathrm{C}_{19}$} & $1.027(8)$ & $0.06(7)$ & \multirow{4}{*}{$\begin{array}{l}\mathbf{H}_{191} \\
\mathbf{H}_{192}\end{array}$} & \multirow{4}{*}{$\begin{array}{l}1.27(4) \\
1.27(4)\end{array}$} & \multirow{2}{*}{$0.11(4)$} & \multirow{4}{*}{0.28} \\
\hline & & & & & & \\
\hline $\mathrm{C}_{16}$ & $1.069(7)$ & $0.08(6)$ & & & & \\
\hline $\mathrm{C}_{15}$ & $1.048(7)$ & $0.08(6)$ & & & & \\
\hline $\mathrm{C}_{14}$ & $1.002(7)$ & $-0.52(7)$ & $\mathbf{H}_{14}$ & $1.44(6)$ & $0.34(4)$ & -0.18 \\
\hline $\mathrm{C}_{17}$ & $1.026(7)$ & $-0.22(6)$ & $\mathbf{H}_{17}$ & $1.34(5)$ & $0.27(4)$ & 0.05 \\
\hline $\mathrm{C}_{12}$ & $1.045(7)$ & $0.00(6)$ & & & & \\
\hline $\mathrm{C}_{13}$ & $1.038(7)$ & $-0.00(6)$ & & & & \\
\hline $\mathrm{C}_{4}$ & $1.035(7)$ & $-0.08(6)$ & & & & \\
\hline $\mathrm{C}_{3}$ & $1.068(7)$ & $0.01(6)$ & & & & \\
\hline \multirow[t]{2}{*}{$\mathrm{C}_{11}$} & $1.012(7)$ & $-0.39(7)$ & \multirow{11}{*}{$\begin{array}{l}\mathbf{H}_{111} \\
\mathbf{H}_{112} \\
\mathbf{H}_{101} \\
\mathbf{H}_{102} \\
\mathbf{H}_{61} \\
\mathbf{H}_{62} \\
\mathbf{H}_{81} \\
\mathbf{H}_{82} \\
\mathbf{H}_{71} \\
\mathbf{H}_{72}\end{array}$} & $1.37(4)$ & $0.23(3)$ & \multirow[b]{2}{*}{0.07} \\
\hline & & & & $1.37(4)$ & $0.23(3)$ & \\
\hline \multirow[t]{2}{*}{$\mathrm{C}_{10}$} & $1.014(8)$ & $-0.29(8)$ & & $1.34(4)$ & $0.20(3)$ & \multirow{3}{*}{0.11} \\
\hline & & & & $1.34(4)$ & $0.20(3)$ & \\
\hline \multirow[t]{2}{*}{$\mathbf{C}_{6}$} & $1.008(7)$ & $-0.43(7)$ & & $1.37(4)$ & $0.23(3)$ & \\
\hline & & & & $1.37(4)$ & $0.23(3)$ & \multirow[t]{2}{*}{0.03} \\
\hline \multirow[t]{2}{*}{$\mathrm{C}_{8}$} & $1.041(8)$ & $-0.01(7)$ & & $1.32(4)$ & $0.15(4)$ & \\
\hline & & & & $1.32(4)$ & $0.15(4)$ & \multirow[t]{2}{*}{0.29} \\
\hline \multirow[t]{2}{*}{$\mathbf{C}_{7}$} & $1.011(7)$ & $-0.41(8)$ & & $1.36(5)$ & $0.21(4)$ & \\
\hline & & & & $1.36(5)$ & $0.21(4)$ & \multirow[t]{2}{*}{0.01} \\
\hline $\mathrm{C}_{5}$ & $1.046(7)$ & $0.07(6)$ & & & & \\
\hline $\mathbf{O}_{20}$ & $1.002(3)$ & $-0.21(4)$ & & & & \\
\hline $\mathbf{O}_{18}$ & $1.001(3)$ & $-0.12(4)$ & & & & \\
\hline $\mathbf{N}_{21}$ & $0.984(5)$ & $-0.43(5)$ & & & & \\
\hline $\mathbf{N}_{9}$ & $1.018(5)$ & $-0.11(5)$ & & & & \\
\hline
\end{tabular}

Electrostatic Potential of 7. The electrostatic potential was calculated using the refined electron density parameters for an isolated molecule of 7 from the crystal. ${ }^{13}$ The extent of the positive (electrophilic) and negative (nucleophilic) 3D isopotential surfaces is shown in Figure 6. The polar character of 7 is clearly depicted in this figure that compares the electrostatic potential property calculated after the multipole fit and the $\kappa$-refinements, respectively. The main difference between the results obtained from the two refinements appears in the extent of the $-0.1 \mathrm{e}^{-1}\left(1 \mathrm{e}^{2} \AA^{-1}=332.4\right.$ $\mathrm{kcal} / \mathrm{mol}$ ) negative electrostatic potential surface surrounding the oxygen atoms of the dioxole ring. As shown in Figure 6, this negative electrostatic potential essentially originates from the high concentration of the electron density in the nitrile group on the one hand, and from the delocalized $\pi$-electrons of the 
phenyl ring on the other hand. The minimum of the electrostatic potential $\left(\mathrm{V}_{\min }=-0.28 \mathrm{e} \AA^{-1}\right.$ from the multipole refinement and $\mathrm{V}_{\min }=-0.24 \mathrm{e} \AA^{-1}$ from the $\kappa$-refinement) is found in the vicinity of the $\mathrm{N}_{21}$ atom. However, the short-range contribution of the oxygen lone pairs to the electrostatic potential is lost in the $\kappa$-refinement based on the restricted monopole model. The minimum of $-0.25 \mathrm{e} \AA^{-1}$ found close to the $\mathrm{O}_{18}$ atom using the full set of multipole parameters is reduced to $-0.10 \mathrm{e} \AA^{-1}$ obtained from the $\kappa$ refinement monopoles. On the other hand, the $+0.20 \mathrm{e}^{-1}$ isopotential surface extent is approximately identical for the two refinement types. Furthermore, it appears in Figure 6 that the pyrrolidine area exhibits an electrophilic character. This also holds for the methylenes at $\mathrm{C}_{19}$ (dioxole ring), $\mathrm{C}_{10}$ and $\mathrm{C}_{11}$ (azepine ring). Therefore, the electrophilic potential is mainly generated by the peripheral positively charged hydrogen atoms of the methylene groups that counterbalance the contribution of the electronegative atoms. In Figure 7 is plotted the isodensity $\left(0.007 \mathrm{e} \AA^{-3}\right)$ molecular surface ${ }^{45-47}$ colored in harmony with the electrostatic potential obtained from the multipole refinement.

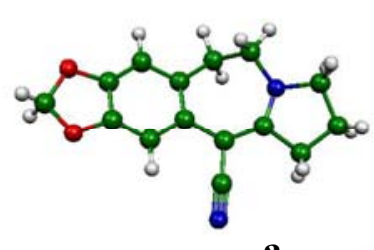

a

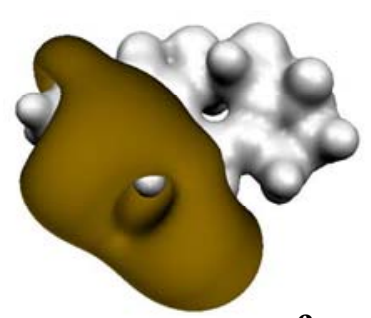

c

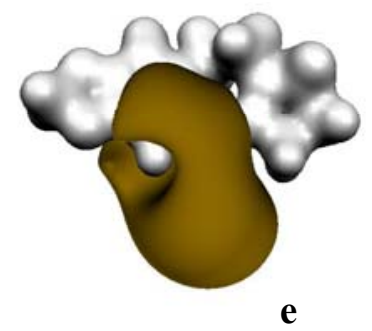

e

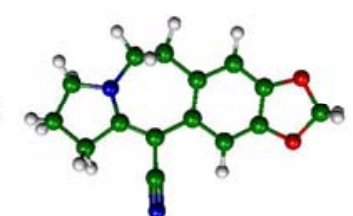

b

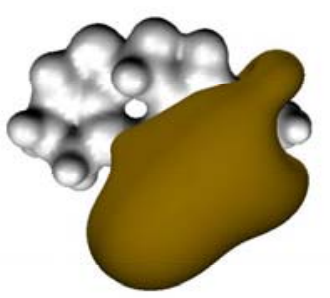

d

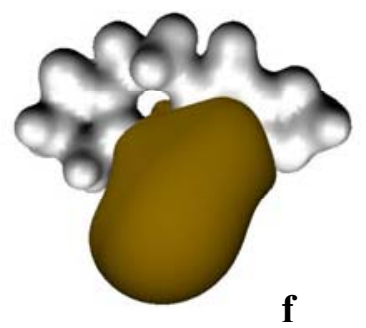

FIGURE 6. 3D isopotential surfaces for two orientations of 7. Grey and brown surfaces correspond to $+0.20 \mathrm{e}^{-1}$ and $-0.10 \mathrm{e}^{-1}$, respectively. (6a) : front view molecular structure; $(6 \mathrm{~b})$ : front view, multipole refinement; $(6 \mathrm{c})$ : front view, $\kappa$ refinement; $(6 \mathrm{~d})$ : back view molecular structure; (6e) : back view, multipole refinement, (6f) : back view, $\kappa$ refinement.

This representation ${ }^{47}$ is convenient in order to qualitatively analyze the topological features of the electrostatic potential, ${ }^{48}$ and hence to help in the prediction of the non-covalent interactions generally 
occurring at the molecular surface (van der Waals interactions, electrostatic complementarities in keylock interactions, etc.). Besides the most negative region (red areas) and the most positive one (dark blue areas confined to the hydrogen positions), the chromatic scale and the width of the stripes in Figure 7 characterize the gradient of the electrostatic potential on the molecular surface; narrower are the stripes, higher is the surface electric field modulus. The gradient directed from the positive (pyrrolidine ring) to the negative part of the molecule (dioxole and nitrile groups) emphasizes its polarity. In Figure $7 \mathrm{~b}$, the back view of the molecular electrostatic potential shows that the nucleophilic area surrounding the nitrile group is extended toward the phenyl ring. This negative electrostatic potential region is, however, more confined on the top surface (front view) of the molecule, as shown in Figure 7a.
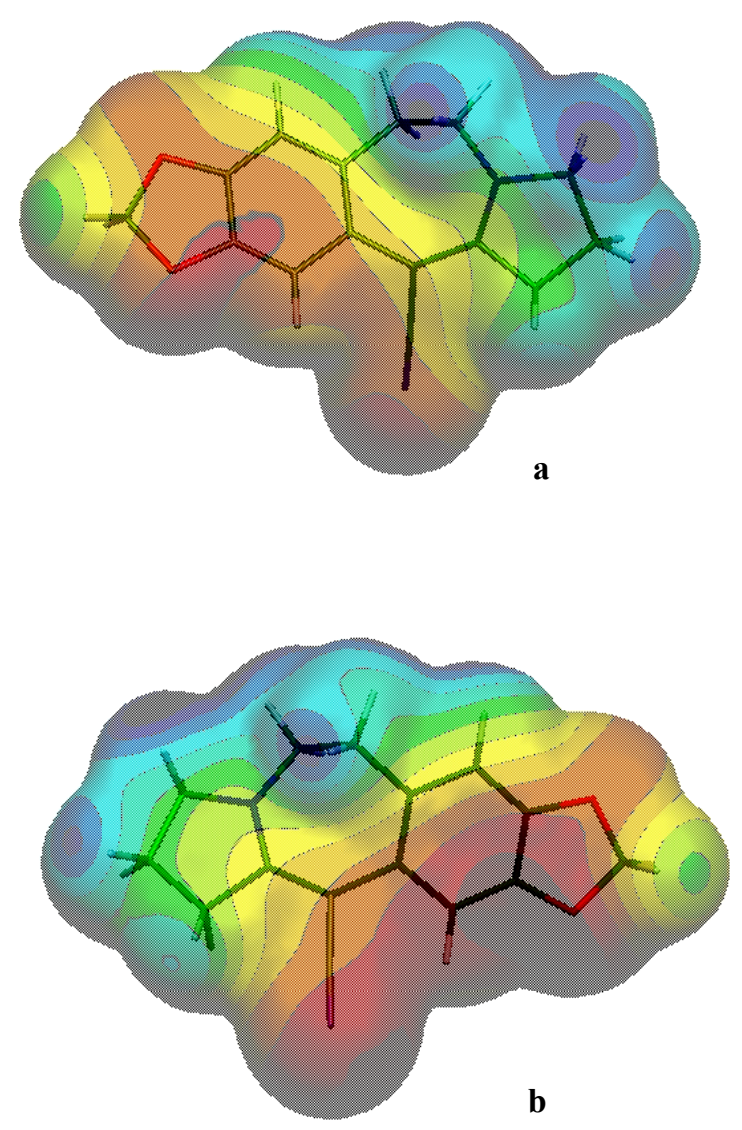

FIGURE 7. $3 \mathrm{D}$ isodensity $\left(0.007 \mathrm{e}^{-3}\right)$ molecular surface colored in accordance with the electrostatic potential obtained from the multipole refinement of 7 . Red and dark blue areas correspond to $\mathrm{V}=-0.20 \mathrm{e} \AA^{-1}$ and $\mathrm{V}=$ $+0.20 \mathrm{e}^{-1}$, respectively. Intermediate values are colored from orange to light blue (10 intervals). (7a) : front view ; (7b) : back view. 


\section{Discussion}

Consider first the reactivity of $\mathbf{2}$ toward nucleophiles. Because of the marked delocalization of the $\mathrm{N}_{9}$-lone pair orbital along the enaminonitrile moiety of $\mathbf{2}$, a significant lowering of the amide resonance, which should involve this lone pair and the vicinal carbonyl at $\mathrm{C}_{8}$, was expected. The weakness of the amide resonance in 2 was emphasized by the fact that the $\mathrm{N}_{9}-\mathrm{C}_{8}$ bond length $(1.397 \AA)$ is significantly higher than the corresponding distances in five-membered lactams $11^{49}(1.350 \AA), \mathbf{1 2}^{3 \mathrm{c}}$ $(1.336 \AA)$ and $N$-methylpyrrolidone $(13)^{50}(1.345 \AA)$ depicted in Figure 8 ; the bond lengths were retrieved from the Cambridge Crystallographic Data Centre (CCDC). ${ }^{51}$ On the other hand, the IR data for 2 reveals a carbonyl absorption $\left(1743 \mathrm{~cm}^{-1}\right)$ much closer to the values observed for five-membered cyclanones (e.g.: 2-methylcyclopentanone, $\left.14: 1734 \mathrm{~cm}^{-1}\right)$ than for five-membered lactams $\left(\mathbf{1 1}^{49}: 1664\right.$ $\left.\mathrm{cm}^{-1} ; 13: 1660 \mathrm{~cm}^{-1}\right)$. Consequently, a substantial electrophilic character would be anticipated for this carbonyl group. In agreement with this prediction, we have established that the carbonyl of 2 is uniformly implicated during the interaction with a variety of nucleophiles (Scheme 1). Regarding the reaction of 7 with nucleophiles, the most striking aspect is the complete lack of reactivity of the enaminonitrile moiety. The reaction with methylmagnesium bromide, for example, involves the dioxole ring of 7, yielding 9 and 10, the enaminonitrile group remaining unchanged in all cases (Scheme 2). From structural considerations, a first observation can be done via the inspection of the molecular conformations and atomic bond lengths determined in $\mathbf{2}$ and 7, compared to those obtained for similar compounds containing the enaminonitrile moiety and extracted from the CCDC. ${ }^{51}$

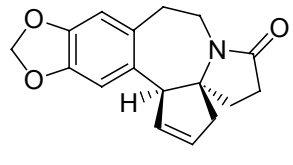

11

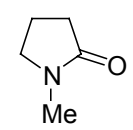

13

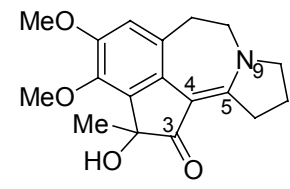

16
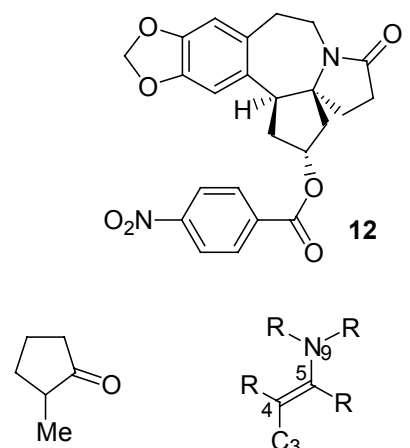

14
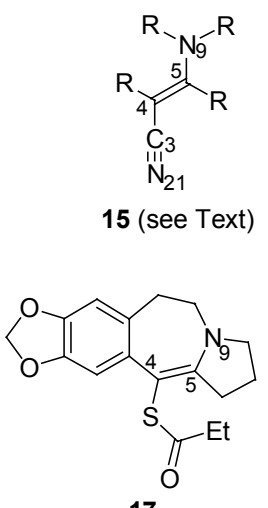

17

FIGURE 8. Reference molecules retrieved from the CCDC. The cephalotaxine numbering system was used for compounds 15, 16 and 17. 
Among the 78 molecules found in this database, 48 correspond to $\mathrm{R}=$ alkyl or aryl groups (15, Figure 8). The average values of the enaminonitrile moiety interatomic distances for $\mathbf{1 5}$ are reported in Table 5. The values obtained for 2 and 7 (Table 5) are globally in a good agreement with those found in the $\mathrm{CCDC}^{51}$, and those previously reported from a multipole electron density study. ${ }^{52}$ Similar bond length values were reported for related enamines $16^{53}$ and $17^{54}$ possessing a pyrrolobenzazepine core (Figure 8 and Table 5).

TABLE 5. Comparison of the Bond Lengths

\section{$(\AA)$ in Enaminonitrile Moieties and in}

\section{Related Fragments}

\begin{tabular}{ccccc}
\hline & $\mathbf{N}_{\mathbf{9}}-\mathbf{C}_{\mathbf{5}}{ }^{\mathbf{a}}$ & $\mathbf{C}_{\mathbf{5}}-\mathbf{C}_{\mathbf{4}}{ }^{\mathbf{a}}$ & $\mathbf{C}_{\mathbf{4}}-\mathbf{C}_{\mathbf{3}}{ }^{\mathbf{a}}$ & $\mathbf{C}_{\mathbf{3}}-\mathbf{N}_{\mathbf{2 1}}{ }^{\mathbf{a}}$ \\
\hline $\mathbf{2}$ & 1.379 & 1.366 & 1.444 & 1.150 \\
$\mathbf{7}$ & 1.342 & 1.389 & 1.424 & 1.165 \\
$\mathbf{1 5}^{\mathbf{b}}$ & 1.370 & 1.395 & 1.424 & 1.145 \\
$\mathbf{1 6}^{\mathbf{b}}$ & 1.369 & 1.389 & 1.421 & \\
$\mathbf{1 7}^{\mathbf{b}}$ & 1.357 & 1.359 & & \\
& & & &
\end{tabular}

${ }^{\text {a }}$ The cephalotaxine numbering system was used here.

${ }^{\mathrm{b}}$ For the structures of 15, 16 and 17, see Figure 8.

The enaminonitrile motif $\mathbf{A}$ is a prototype of "push-pull ethylene" which largely exists in canonical resonance form $\mathbf{B}$, involving a formal rehybridization of the ground state structure $\mathbf{A}$ (Scheme 3). Accordingly, the $\mathrm{N}_{9}-\mathrm{C}_{5}$ bond should shorten $\left(\mathrm{Nsp}^{3}-\mathrm{Csp}^{2} \rightarrow \mathrm{Nsp}^{2}=\mathrm{Csp}^{2}\right)$, the $\mathrm{C}_{5}-\mathrm{C}_{4}$ bond should lengthen $\left(\mathrm{Csp}^{2}=\mathrm{Csp}^{2} \rightarrow \mathrm{Csp}^{2}-\mathrm{Csp}^{2}\right)$, the $\mathrm{C}_{4}-\mathrm{C}_{3}$ bond should shorten $\left(\mathrm{Csp}^{2}-\mathrm{Csp} \rightarrow \mathrm{Csp}^{2}=\mathrm{Csp}\right)$ and the $\mathrm{C}_{3}-\mathrm{N}_{21}$ bond should lengthen $\left(\mathrm{Csp} \equiv \mathrm{Nsp} \rightarrow \mathrm{Csp}=\mathrm{Nsp}^{2}\right)$ to some extent. On the other hand, the greater the $\mathrm{N}_{9}$ lone pair delocalizes in the enaminonitrile system, the higher the population of the zwitterionic species B. This is illustrated by comparing the enaminonitrile bond lengths of 7 with those of its progenitor 2 (Table 5). 


\section{SCHEME 3. Resonance Picture of the}

\section{$\beta$-Enaminonitrile Motif}

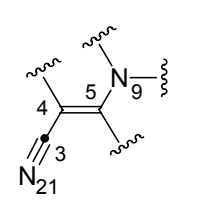

A

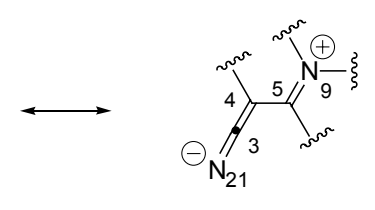

B

In 7 the $\mathrm{N}_{9}-\mathrm{C}_{5}$ bond is shortened by $0.037 \AA$, the $\mathrm{C}_{5}-\mathrm{C}_{4}$ bond is lengthened by $0.023 \AA$, the $\mathrm{C}_{4}-\mathrm{C}_{3}$ bond is shortened by $0.020 \AA$ and the $\mathrm{C}_{3}-\mathrm{N}_{21}$ bond is lengthened by $0.015 \AA$, a phenomenon which can be interpreted by assuming that the $\mathrm{N}_{9}$ lone pair in 7 is completely delocalized over the enaminonitrile moiety, while in $\mathbf{2}$ the delocalization is less pronounced, because of the competitive participation of the lone pair in the amide resonance. This electron delocalization is likely responsible for the weakness of the electrophilic potential of $\mathrm{C}_{3}$ and $\mathrm{C}_{5}$ atoms. Breneman and Moore have recently reported a theoretical study of the enaminonitrile pattern and its rotational transition states. ${ }^{9}$ This work was based on ab initio $\mathrm{HF} / 6-31 \mathrm{G}^{* *}$ calculations which were used to derive the molecular conformations and the atomic charges. The calculated bond lengths for the planar form of this fragment were $\mathrm{N}_{9}-\mathrm{C}_{5}=1.331 \AA, \mathrm{C}_{5}-\mathrm{C}_{4}$ $=1.355 \AA, \mathrm{C}_{4}-\mathrm{C}_{3}=1.432 \AA$ and $\mathrm{C}_{3}-\mathrm{N}_{21}=1.138 \AA$ (cephalotaxine numbering system). ${ }^{23}$ These values are in good agreement with the experimental bond lengths reported in Table 5 and confirm the electron delocalization along the enaminonitrile moiety. Another geometrical argument is the observed planarity at the enamine nitrogen center in $\mathbf{2}$ and $\mathbf{7}$ (the sums of the angles around $\mathrm{N}_{9}$ are very close to $360^{\circ}$, see Table 2). The pyramidality at the nitrogen atom site was carefully analyzed by Brown and co-workers for a series of crystalline enamines. ${ }^{55}$ The authors have shown that the pyramidality is less marked for molecules where the nitrogen is engaged in five-membered rings than those where the $\mathrm{N}$-atom is part of six-membered rings, and have demonstrated how the nitrogen pyramidality can cause C-N bond strains in these molecules. As also pointed out by these authors, the decrease of the enamine nitrogen pyramidality is an evidence of the hybridization change from $\mathrm{sp}^{3}$ to $\mathrm{sp}^{2} \mathrm{~N}$-atom. Comparatively, in 2 and 7, the corresponding $\mathrm{N}_{9}$ is linking the azepine and pyrrolidine nuclei. It is noteworthy that for both $\mathbf{2}$ and 7, the flexibility of the $\mathrm{C}_{12}-\mathrm{C}_{11}-\mathrm{C}_{10}-\mathrm{N}_{9}$ azepine fragment prevents any alteration of planarity imposed at the $\mathrm{N}_{9}$ site (ring strain relief), this in agreement with the results of Brown and co-workers. ${ }^{55}$ For compounds 15 found in the CCDC, ${ }^{51}$ the average angle sum around the $\mathrm{N}$ atom is $<357.7^{\circ}>$, and less than $10 \%$ of the retrieved fragments have an angle smaller than $357^{\circ}$; the minimum value found is $331.7^{\circ}$. In comparison, the cephalotaxine nitrogen atom displays an angle sum of $333.1(1)^{\circ}$ for the two molecules in the asymmetric unit. ${ }^{56}$ 
Before examining the reactivity of the 1,3-dioxole ring of 7 toward $\mathrm{MeMgBr}$, it is necessary to consider the geometrical features of this element. The conformational stabilization of the 1,3benzodioxole has been extensively studied from both experimental spectroscopic evidence and theoretical calculations. ${ }^{57-59}$ Moon and co-workers have established that 1,3-benzodioxole has a lower puckering barrier to planarity than 1,3-dioxole, due to the suppression of the anomeric effect caused by the phenyl nucleus. ${ }^{59}$ This result is in agreement with our experimental dihedral angles values observed in 2 and 7 (puckering angle $\tau=<1.61^{\circ}>$ and flapping angle $\varphi=<11.77^{\circ}>$ ). These values are in the same order of magnitude than the averaged ones calculated from 401 hits leading to 522 1,3-dioxole fragments found in the CCDC: $\tau \in\left[0,46^{\circ}\right]$ and $\varphi \in\left[0,17^{\circ}\right] .{ }^{51}$ Furthermore, the inspection of atomic bond lengths reported in Table 2 shows that the phenyl rings in $\mathbf{2}$ and $\mathbf{7}$ exhibit two halves. The first half, which implicates the $\mathrm{C}_{14}-\mathrm{C}_{13}-\mathrm{C}_{12}-\mathrm{C}_{17}$ fragment (Figure 3), clearly displays longer distances than the second half connected to the dioxole ring, and thus presents a weaker electron delocalization. That would probably induce a significant contribution of the hyperconjugation of the lone pairs of the oxygen atoms and $\mathrm{C}=\mathrm{C}$ antibonding orbitals of the phenyl ring $\left(\mathrm{n}_{\mathrm{p}} \rightarrow \pi^{*}{ }_{\mathrm{C}=\mathrm{C}}\right)$, minimizing the anomeric interaction, according to the description reported by Moon and co-workers. ${ }^{59}$ The experimental electron density determined for 7 more accurately emphasizes the previous observations. One main feature of the static electron deformation density maps (Figure 4b) is the important accumulation $\left(0.60 \mathrm{e} \AA^{-3}\right)$ of electrons in the $\mathrm{N}_{9}-\mathrm{C}_{5}$ bond. In order to better characterize the electron delocalization along the $\mathrm{N}_{21}-\mathrm{C}_{3}-$ $\mathrm{C}_{4}-\mathrm{C}_{5}-\mathrm{N}_{9}$ fragment of 7 (enaminonitrile moiety), we have plotted in Figure 9 the 3D electron deformation density surface corresponding to $+0.05 \mathrm{e} \AA^{-3}$.

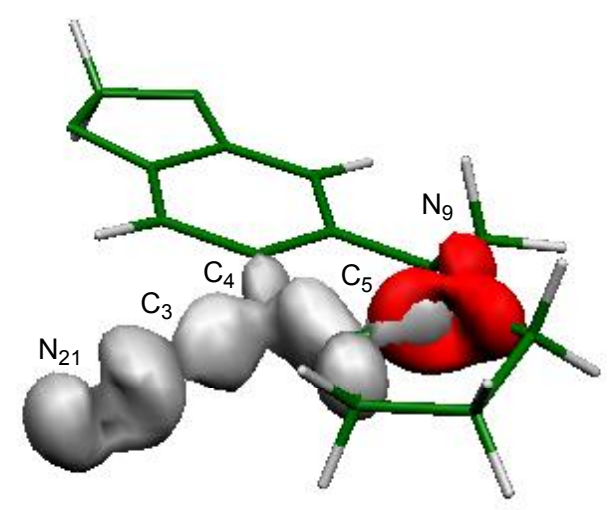

FIGURE 9. Electron deformation isodensity surface $\left(+0.05 \mathrm{e}^{-3}\right)$ of the enaminonitrile moiety of 7 . Red area corresponds to the contribution of the $\mathrm{N}_{9}$ atom. 
The shape of the electron density surface around $\mathrm{N}_{9}$ is particularly interesting. The expectation based on the geometrical consideration above-mentioned for enamines where the planarity at the nitrogen atom imposes a formal $\mathrm{sp}^{2}$ hybridization is verified. ${ }^{55}$ However, while the resonance in enamines is necessarily limited to the $\mathrm{N}-\mathrm{C}=\mathrm{C}$ triad, the electron delocalization in 7 extends along the five-atom enaminonitrile system, with the electron density lobes of the $\mathrm{N}_{9}$ lone pair fully engaged in the $\mathrm{N}_{9}-\mathrm{C}_{5}$ bond (Figure 9). The electron delocalization is also characterized by the electron deformation density peak heights found for $\mathrm{C}_{4}-\mathrm{C}_{5}\left(0.60 \mathrm{e}^{-3}\right)$ and $\mathrm{C}_{3}-\mathrm{C}_{4}\left(0.70 \mathrm{e} \AA^{-3}\right)$ (Figure $\left.4 \mathrm{~b}\right)$, comparable to that of the $\mathrm{N}_{9}-\mathrm{C}_{5}$ bond. Another remarkable electron density feature is the dissymmetry observed in the dioxole ring. The respective $\mathrm{C}-\mathrm{O}$ interatomic distances are practically the same for $\mathrm{O}_{18}$ and $\mathrm{O}_{20}$ atoms (Table 2). However, the electron density peak heights are drastically different. For $\mathrm{O}_{20}$, the electron density is almost equally distributed between the two C-O bonds in the one hand, and the lone pair in the other hand (Figure 4a). Conversely, the $\mathrm{O}_{18}$ lone pair electron deformation density is much more pronounced, disfavoring the electron accumulation in the $\mathrm{O}_{18}-\mathrm{C}_{19}$ bond. $\mathrm{It}$ is also noteworthy that $\mathrm{O}_{18}$ is less involved in hydrogen bonds in the crystal than $\mathrm{O}_{20}$ (Table 2), but this difference between the two oxygen atoms seems to originate from a whole intrinsic molecular character.

From the topological analysis of the total electron density of 7 , the bond ellipticity magnitudes (Table 3) are also pertinent indicators for examining the electron delocalization along the enaminonitrile fragment. Indeed, around the $\mathrm{N}_{9}$ atom, the bond displaying the highest value of $\varepsilon$ is the $\mathrm{N}_{9}-\mathrm{C}_{5}$ one $(\varepsilon=$ 0.24 , compared to 0.13 and 0.17 found for $\mathrm{N}_{9}-\mathrm{C}_{10}$ and $\mathrm{N}_{9}-\mathrm{C}_{8}$, respectively). The $\mathrm{C}_{4}-\mathrm{C}_{5}$ bond has an important ellipticity value (0.31), comparable to those obtained for the phenyl ring ( $\varepsilon=0.21$ to 0.37 ) reported in Table 3. Likewise, the $\mathrm{C}_{3}-\mathrm{C}_{4}$ bond exhibits a relatively high ellipticity $(0.22)$. Note that the theoretical calculations performed on various compounds where such a delocalization is not expected gave ellipticity values very close to zero. ${ }^{60-62}$ On the other hand, the topological properties of the dioxole ring reveal particular features. The $\mathrm{C}_{19}-\mathrm{O}_{18}$ bond presents the highest ellipticity $(\varepsilon=0.27)$ in this ring and the lowest electron density at the bond critical point. The value of the Laplacian $\left(-5.13 \mathrm{e} \AA^{-5}\right)$ of the $\mathrm{C}_{19^{-}}$ $\mathrm{O}_{18}$ bond is the minimum found for all bonds in 7 including $\mathrm{C}_{19}-\mathrm{O}_{20}\left(\nabla^{2} \rho(\mathbf{r})=-9.21\right.$ e $\left.\AA^{-5}\right)$. This emphasizes the dissymmetry of the electron properties of the 1,3-dioxole ring in 7, prefiguring the predominant cleavage of the $\mathrm{C}_{19}-\mathrm{O}_{18}$ bond (the nucleophilic attack of 7 by MeMgBr actually yields 9 and 10 in the respective ratio of 2.4:1). However, all efforts at adding a variety of nucleophilic species to the enaminonitrile moiety of 7, employing a wide range of operating conditions, were fruitless. That failure can be interpreted in light of the atomic net charges obtained for 7. The expectation of a nucleophilic attack on $\mathrm{C}_{3}$ or $\mathrm{C}_{5}$ centers requires a marked electrophilic character for these atoms. It is not the case, since we have seen that the electron density in the enaminonitrile moiety of 7 is completely delocalized (Figure 9). This feature remains in the net atomic charge repartition. Indeed, the three carbon atoms of 
the enaminonitrile part are almost neutral (Table 4). The main negative charge is carried by the $\mathrm{N}_{21}$ atom (-0.43 e), compared to -0.11 e found for $\mathrm{N}_{9}$, a value which is in excellent agreement with the Mulliken populations obtained from theoretical calculations on molecules displaying a nitrile group. ${ }^{63-67}$ However, in these studies, the nitrile carbon atom has an average charge of $+0.30 \mathrm{e}$, while the corresponding value in 7 is $0.01(6)$ e. The polarity of the nitrile in 7 is thus locally inhibited, preventing any nucleophilic attack on $\mathrm{C}_{3}$ center. Regarding the enaminonitrile pattern, Breneman and Moore have also reported atomic charges from quantum mechanics calculations. ${ }^{9}$ Two sets of charges were presented: the first set was obtained from the fit to the electrostatic potential and the second one was derived from the topological properties. No quantitative agreement can be found with our results, given the model dependence of the atomic charges. However, the "push-pull effect" observed in the enaminonitrile fragment is recovered from both theoretical and experimental approaches. On the other hand, the easiest cleavage of $\mathrm{C}_{19}-\mathrm{O}_{18}$ bond observed during the reaction of 7 with methylmagnesium bromide, affording 9 and $\mathbf{1 0}$ regioisomers in the respective ratio of 2.4:1, can be simply explained by the crude difference between the oxygen atomic charges $\left(-0.12(4)\right.$ e for $\mathrm{O}_{18}$ and $-0.21(4)$ e for $\left.\mathrm{O}_{20}\right)$.

Finally, from the inspection of the electrostatic potential generated around 7 , it is possible to rationalize the very low reactivity of this molecule toward nucleophiles. Figures 6 and 7 clearly demonstrate the global polar character of 7 , the negative region all surrounding the nitrile group. The large extent of this negative part of the electrostatic potential (Figure 6) makes the approach of a nucleophile toward the nitrile area very unlikely. This also appears in Figure 7 where the electrostatic potential is represented on the interacting surface of the molecule. Interestingly, the cleavage of the

dioxole ring observed in the reaction of 7 with methylmagnesium bromide correlates well with the examination of the electrostatic potential. The electrophilic character of 7 in the vicinity of $\mathrm{C}_{19}$ is indeed well reproduced. This is especially clear in Figure $6 \mathrm{~b}$ (multipole refinement) where the positive potential of the $\mathrm{C}_{19}$ methylene group emerges from the surrounding negative surfaces generated around $\mathrm{O}_{18}$ and $\mathrm{O}_{20}$ atoms.

\section{Conclusion}

In connection with our efforts directed toward the synthesis of 1a, we have examined the addition of nucleophilic reagents on $\beta$-enaminonitriles 2 and 7 possessing a pyrrolobenzazepine core. In fact, the carbonyl group of $\mathbf{2}$ is uniformly implicated during the interaction with a variety of nucleophiles, revealing its marked electrophilic character. Regarding 7, the most striking aspect is the complete lack of reactivity of the enaminonitrile moiety; the reaction with methylmagnesium bromide, for example, involves exclusively the cleavage of the dioxole ring. The unexpected reactivity of 2 and 7 toward nucleophiles was rationalized with the help of crystallographic studies of $\mathbf{2}$ and $\mathbf{7}$ and an 
experimental electron density characterization of 7. The great reactivity of the carbonyl group of 2 was interpreted by invoking the weakness of the amide resonance, due to a pronounced delocalization of the $\mathrm{N}_{9}$ lone pair over the enaminonitrile moiety. On the other hand, the electron density delocalization in the enaminonitrile system of 7 has been clearly highlighted and quantified. The lack of reactivity of the enaminonitrile moiety of 7 toward nucleophiles was here demonstrated, the system being locked by the electron delocalization in the enaminonitrile part, caused by the "push-pull effect" between the two nitrogen atoms. Note that, being the only method known to date to assess experimentally the bond geometries, the static electron deformation densities, the topological properties (bond nature and electron density repartition), as well as the atomic charges and surface electrostatic potentials of a given molecule, the crystallographic/electron density characterization used throughout the present paper constitutes an outstanding advance in the rationalization/prediction of structure-(re)activity relationships in Chemistry, Biology, etc. The lack of reactivity of the enaminonitrile system of 7 is quite vexing, since the so-called "Weinreb's enamine" (compound equivalent to 7, in which the nitrile group was replaced by a hydrogen atom) has been used as key intermediate in the first total synthesis of 1a, taking advantage of its marked nucleophilic properties. ${ }^{68}$ In light of this, it is clear that the electronwithdrawing effect induced by the nitrile group in 7 is counterbalanced by the electron-donating amino group in the $\beta$-position, resulting in a dramatic decrease in reactivity of the enaminonitrile system. At this juncture, it was of prime importance to lower the electron density in the enaminonitrile moiety of 7 , with the aim of making the addition of a nucleophile feasible. The experience gained during the course of this study may have paved the way for an eventual solution to this problem. In this respect, the important difference in atomic charge between the two nitrogen centers of $7\left(\mathrm{~N}_{9}:-0.11\right.$ e, $\mathrm{N}_{21}:-0.43$ e, Table 4) suggested to us that the nitrile end should be able to complex chemoselectively a variety of Lewis acids, hence lowering the electron density in the enaminonitrile system. The feasibility of such an approach is currently being evaluated in our laboratories.

\section{Experimental Section}

\section{5,8,9,10-Tetrahydro-8-hydroxy-8-allyl-6H-1,3-dioxolo[4,5-h]pyrrolo[2,1-b][3]benzazepine-11-}

carbonitrile (3). To a solution of $\mathrm{CuBr} . \mathrm{SMe}_{2}(92 \mathrm{mg}, 0.45 \mathrm{mmol})$ in THF $(10 \mathrm{~mL})$ was added at $-78{ }^{\circ} \mathrm{C}$ allylmagnesium bromide $\left(4.5 \mathrm{~mL}\right.$ of a $1 \mathrm{M}$ solution in $\left.\mathrm{Et}_{2} \mathrm{O}, 4.5 \mathrm{mmol}\right)$ and the solution was stirred for

$20 \mathrm{~min}$ at this temperature. A solution of nitrile $2^{4}(0.4 \mathrm{~g}, 1.5 \mathrm{mmol})$ in THF $(60 \mathrm{~mL})$ was added and the resulting mixture was stirred at $-78{ }^{\circ} \mathrm{C}$ for $45 \mathrm{~min}$. A saturated aqueous solution of $\mathrm{NH}_{4} \mathrm{Cl}(50 \mathrm{~mL})$ was then added at $-78^{\circ} \mathrm{C}$. The aqueous layer was separated and extracted with AcOEt $(3 \times 50 \mathrm{~mL})$. The combined organic layers were washed with brine $(10 \mathrm{~mL})$, dried $\left(\mathrm{MgSO}_{4}\right)$ and concentrated in vacuo. The residue was purified by flash chromatography $\left(\mathrm{SiO}_{2}, 6: 1 \mathrm{CH}_{2} \mathrm{Cl}_{2} / \mathrm{AcOEt}\right.$ ) to give 3 (415 $\mathrm{mg}, 89 \%$ ) 
as a white solid: $\mathrm{mp} 140-146{ }^{\circ} \mathrm{C}$ (dec); IR (KBr pellet) $3411,2167 \mathrm{~cm}^{-1} ;{ }^{1} \mathrm{H}$ NMR (400 MHz, DMSO$\left.d_{6}\right) \delta 1.85-1.90(\mathrm{~m}, 1 \mathrm{H}), 2.15-2.24(\mathrm{~m}, 1 \mathrm{H}), 2.34-2.45(\mathrm{~m} 2 \mathrm{H}), 2.76-2.84(\mathrm{~m}, 2 \mathrm{H}), 2.92-3.03(\mathrm{~m}, 2 \mathrm{H})$, 3.25 (br s, 1H), 3.63 (br s, 1H), 5.10 (d, $J=10.1 \mathrm{~Hz}, 1 \mathrm{H}), 5.16(\mathrm{~d}, J=17.1 \mathrm{~Hz}, 1 \mathrm{H}), 5.66-5.72(\mathrm{~m}, 1 \mathrm{H})$, $5.95(\mathrm{~m}, 2 \mathrm{H}), 6.19$ (br s, $1 \mathrm{H}), 6.70(\mathrm{~s}, 1 \mathrm{H}), 6.80(\mathrm{~s}, 1 \mathrm{H}) ;{ }^{13} \mathrm{C} \mathrm{NMR}\left(100 \mathrm{MHz}, \mathrm{DMSO}-d_{6}\right) \delta 32.6\left(\mathrm{CH}_{2}\right)$, $33.5\left(\mathrm{CH}_{2}\right), 36.4\left(\mathrm{CH}_{2}\right), 43.0\left(\mathrm{CH}_{2}\right), 45.7\left(\mathrm{CH}_{2}\right), 73.7(\mathrm{C}), 98.5(\mathrm{C}), 101.7\left(\mathrm{CH}_{2}\right), 106.2(\mathrm{CH}), 110.5$ $(\mathrm{CH}), 119.9\left(\mathrm{CH}_{2},\right), 123.9(\mathrm{C}), 128.0(\mathrm{C}), 132.4(\mathrm{C}), 133.8(\mathrm{CH}), 145.0(\mathrm{C}), 147.0(\mathrm{C}), 157.8(\mathrm{C})$; Anal. for $\mathrm{C}_{18} \mathrm{H}_{18} \mathrm{~N}_{2} \mathrm{O}_{3}$, calcd. C, 69.43; H, 6.15; N, 8.99; found C, 68.93; H, 6.04; N, 8.71.

\section{5,8,9,10-Tetrahydro-8-hydroxy-8-(1')-ethoxyvinyl-6H-1,3-dioxolo[4,5-h]pyrrolo[2,1-b]-}

[3]benzazepine-11-carbonitrile (4). To a solution of 1-lithio-1-ethoxyethene [prepared by dropwise addition of tert-butyllithium (1.24 $\mathrm{mL}$ of a $1.5 \mathrm{M}$ solution in $n$-pentane, $1.9 \mathrm{mmol})$ to a solution of ethyl vinyl ether $(0.36 \mathrm{~mL}, 3.73 \mathrm{mmol})$ in THF $(1 \mathrm{~mL})$ at $-78^{\circ} \mathrm{C}$, warming on an ice bath until the yellow color is discharged, and immediate recooling to $-78^{\circ} \mathrm{C}$ ] was added dropwise a solution of nitrile 2 (50 $\mathrm{mg}, 0.19 \mathrm{mmol})$ in THF $(2.3 \mathrm{~mL})$. The resulting mixture was stirred at $-78{ }^{\circ} \mathrm{C}$ for $15 \mathrm{~min}$, allowed to warm to $0{ }^{\circ} \mathrm{C}$ and stirred for an additional $15 \mathrm{~min}$. A 1:1 solution of saturated aqueous $\mathrm{NH}_{4} \mathrm{Cl}$ and $\mathrm{MeOH}(4 \mathrm{~mL})$ was then added dropwise at $0{ }^{\circ} \mathrm{C}$. The aqueous layer was separated and extracted with $\mathrm{Et}_{2} \mathrm{O}(2 \times 10 \mathrm{~mL})$. The combined organic layers were washed with brine $(5 \mathrm{~mL})$, dried $\left(\mathrm{Na}_{2} \mathrm{CO}_{3}\right)$ and concentrated in vacuo. The residue was purified by flash chromatography $\left(\mathrm{SiO}_{2}, \quad 9: 1\right.$ cyclohexane/AcOEt,) to give adduct 4 (37 mg, 54\%) as an orange solid: $\mathrm{mp} 71-72{ }^{\circ} \mathrm{C}$ (dec); IR (neat) 3358, $2186 \mathrm{~cm}^{-1} ;{ }^{1} \mathrm{H}$ NMR (400 MHz, $\left.\mathrm{CDCl}_{3}\right) \delta 1.30$ (t, $\left.J=7.0 \mathrm{~Hz}, 3 \mathrm{H}\right), 2.05$ (ddd, $J=7.0,9.0,13.6$ Hz, 1H), 2.46 (ddd, $J=5.5,9.3,13.6 \mathrm{~Hz}, 1 \mathrm{H}), 2.78$ (dt, $J=14.7,4.5 \mathrm{~Hz}, 1 \mathrm{H}), 2.84$ (dt, $J=14.7,4.3 \mathrm{~Hz}$, 1H), 3.07 (ddd, $J=16.0,9.0,7.0 \mathrm{~Hz}, 1 \mathrm{H}), 3.17$ (ddd, $J=16.0,9.3,5.5 \mathrm{~Hz}, 1 \mathrm{H}), 3.19$ (br s, 1H), 3.40 (br s, 2H), $3.79(\mathrm{~m}, 2 \mathrm{H}), 4.19(\mathrm{~d}, J=2.6 \mathrm{~Hz}, 1 \mathrm{H}), 4.45(\mathrm{~d}, J=2.6 \mathrm{~Hz}, 1 \mathrm{H}), 5.90(\mathrm{~s}, 2 \mathrm{H}), 6.47$ (s, $1 \mathrm{H}), 7.03$ $(\mathrm{s}, 1 \mathrm{H}) ;{ }^{13} \mathrm{C} \mathrm{NMR}\left(50 \mathrm{MHz}, \mathrm{CDCl}_{3}\right) \delta 14.3\left(\mathrm{CH}_{3}\right), 32.5\left(\mathrm{CH}_{2}\right), 35.5\left(\mathrm{CH}_{2}\right) 36.1\left(\mathrm{CH}_{2}\right), 46.0\left(\mathrm{CH}_{2}\right), 63.7$ $\left(\mathrm{CH}_{2}\right), 75.6(\mathrm{C}), 83.7\left(\mathrm{CH}_{2}\right), 97.5(\mathrm{C}), 100.9\left(\mathrm{CH}_{2}\right), 106.8(\mathrm{CH}), 109.1(\mathrm{CH}), 123.5(\mathrm{C}), 126.8(\mathrm{C}), 131.5$ (C), 144.8 (C), 146.5 (C), 157.4 (C), 159.4 (C); Anal. for $\mathrm{C}_{19} \mathrm{H}_{20} \mathrm{~N}_{2} \mathrm{O}_{4}$, calcd. C, 67.05; H, 5.92; N, 8.23; found $\mathrm{C}, 66.84 ; \mathrm{H}, 6.05 ; \mathrm{N}, 8.17$.

\section{5,8,9,10-Tetrahydro-8-hydroxy-6H-1,3-dioxolo[4,5-h]pyrrolo[2,1-b][3]-benzazepine-11-}

carbonitrile (5). To a solution of nitrile $2(0.6 \mathrm{~g}, 2.23 \mathrm{mmol})$ in $\mathrm{EtOH}(25 \mathrm{~mL})$ was added sodium borohydride $(0.33 \mathrm{~g}, 8.7 \mathrm{mmol})$. The mixture was stirred for $1 \mathrm{~h}$ at $20{ }^{\circ} \mathrm{C}$ and hydrolyzed with a $1.2 \mathrm{~N}$ aqueous solution of $\mathrm{HCl}(10 \mathrm{~mL})$ at $0{ }^{\circ} \mathrm{C}$. The aqueous layer was separated and extracted with $\mathrm{Et}_{2} \mathrm{O}$ $(2 \times 10 \mathrm{~mL})$. The combined organic layers were washed with a saturated aqueous solution of sodium hydrogencarbonate $(5 \mathrm{~mL})$, dried $\left(\mathrm{MgSO}_{4}\right)$ and concentrated in vacuo. The residue was purified by flash chromatography $\left(\mathrm{SiO}_{2}, 9: 1 \mathrm{CH}_{2} \mathrm{Cl}_{2} / \mathrm{AcOEt}\right.$, ) to give 5 as a white solid $(0.45 \mathrm{~g}, 75 \%): \mathrm{mp} 163-165{ }^{\circ} \mathrm{C}$ 
(dec); IR (neat) 3378, $2170 \mathrm{~cm}^{-1} ;{ }^{1} \mathrm{H}$ NMR (400 MHz, $\left.\mathrm{CDCl}_{3}\right) \delta 1.84-1.99(\mathrm{~m}, 1 \mathrm{H}), 2.26-2.51(\mathrm{~m}, 2 \mathrm{H})$, $2.93(\mathrm{~m}, 2 \mathrm{H}), 2.95-3.27(\mathrm{~m}, 2 \mathrm{H}), 3.54-3.75(\mathrm{~m}, 2 \mathrm{H}), 5.11-5.17(\mathrm{~m}, 1 \mathrm{H}), 5.95(\mathrm{~s}, 2 \mathrm{H}), 6.50(\mathrm{~s}, 1 \mathrm{H}), 7.05$ $(\mathrm{s}, 1 \mathrm{H}) ;{ }^{13} \mathrm{C}$ NMR $\left(50 \mathrm{MHz}, \mathrm{DMSO}-d_{6}\right) \delta 30.4\left(\mathrm{CH}_{2}\right), 33.8\left(\mathrm{CH}_{2}\right), 36.1\left(\mathrm{CH}_{2}\right), 49.3\left(\mathrm{CH}_{2}\right), 74.1(\mathrm{C})$, $92.1(\mathrm{CH}), 101.8\left(\mathrm{CH}_{2}\right), 106.2(\mathrm{CH}), 110.6(\mathrm{CH}), 123.8(\mathrm{C}), 128.0(\mathrm{C}), 132.2(\mathrm{C}), 145.1(\mathrm{C}), 147.0(\mathrm{C})$, 157.9 (C); Anal. for $\mathrm{C}_{15} \mathrm{H}_{14} \mathrm{~N}_{2} \mathrm{O}_{3}$, calcd. C, 66.66; H, 5.22; N, 10.36; found C, 66.49; H, 5.10; N, 10.21.

3-[5-Cyano-8,9-dihydro-7H-1,3-dioxolo[4,5-h]benzazepin-6-yl]propenoic acid (6). To a solution of nitrile $2(0.5 \mathrm{~g}, 1.86 \mathrm{mmol})$ in ethylene glycol $(10 \mathrm{~mL})$ and water $(5 \mathrm{~mL})$ was added lithine monohydrate $(0.78 \mathrm{~g}, 18.6 \mathrm{mmol})$ and the resulting mixture was refluxed for $22 \mathrm{~h}$ and extracted with $\mathrm{CH}_{2} \mathrm{Cl}_{2}(3 \times 20$ $\mathrm{mL}$ ). The aqueous phase was separated and acidified by addition of a $6 \mathrm{M}$ aqueous solution of $\mathrm{HCl}$ and then extracted with $\mathrm{CHCl}_{3}(3 \times 50 \mathrm{~mL})$. The organic layer was washed with brine $(2 \times 25 \mathrm{~mL})$, dried $\left(\mathrm{MgSO}_{4}\right)$ and concentrated in vacuo to give 6 as a white solid $\left(0.37 \mathrm{~g}, 65 \%\right.$ ): $\mathrm{mp} 190-192{ }^{\circ} \mathrm{C}$; $\mathrm{IR}(\mathrm{KBr})$ 3332, 2173, $1715 \mathrm{~cm}^{-1}$; ${ }^{1} \mathrm{H}$ NMR (400 MHz, DMSO- $\left.d_{6}\right) \delta 2.40-2.55$ (m, 2H), 2.65-2.80 (m, 2H), 2.80$2.95(\mathrm{~m}, 2 \mathrm{H}), 3.35-3.50(\mathrm{~m}, 2 \mathrm{H}), 3.55-4.50(\mathrm{br} \mathrm{s}, 1 \mathrm{H}), 5.95(\mathrm{~s}, 2 \mathrm{H}), 6.66(\mathrm{~s}, 1 \mathrm{H}), 6.85(\mathrm{~s}, 1 \mathrm{H}), 8.10(\mathrm{~s}$, $1 \mathrm{H}) ;{ }^{13} \mathrm{C}$ NMR (100 MHz, DMSO-d $) \delta 33.7\left(\mathrm{CH}_{2}\right), 34.3\left(\mathrm{CH}_{2}\right), 37.5\left(\mathrm{CH}_{2}\right), 48.6\left(\mathrm{CH}_{2}\right), 77.4(\mathrm{C})$, $101.8\left(\mathrm{CH}_{2}\right), 107.2(\mathrm{CH}), 110.3(\mathrm{CH}), 124.2(\mathrm{C}), 128.5(\mathrm{C}), 133.6(\mathrm{C}), 145.3(\mathrm{C}), 146.8(\mathrm{C}), 157.6(\mathrm{C})$, 174.0 (C); FAB-MS (-9eV) m/z (\% rel intensity) 287.1 (12) $[\mathrm{M}+\mathrm{H}]^{+}, 269.2$ (15), 254.3 (18), 239.3 (63), 226.2 (8), 211,2 (75), 183.3 (6), 136.3 (100); Anal. for $\mathrm{C}_{15} \mathrm{H}_{14} \mathrm{~N}_{2} \mathrm{O}_{4}+\mathrm{H}_{2} \mathrm{O}$, calcd. C, 59.21; H, 5.30; N, 9.21; found C, 58.96; H, 4.63; N, 9.06.

5,8,9,10-Tetrahydro-6H-1,3-dioxolo[4,5-h]pyrrolo[2,1-b][3]benzazepine-11-carbonitrile (7). To a solution of nitrile $2(250 \mathrm{mg}, 0,93 \mathrm{mmol})$ in $\mathrm{THF}(25 \mathrm{~mL})$ at $20{ }^{\circ} \mathrm{C}$ was added a solution of $\mathrm{AlH}_{3}(7 \mathrm{~mL})$ [prepared by dropwise addition of a solution of $\mathrm{AlCl}_{3}(1.1 \mathrm{~g}, 8.2 \mathrm{mmol})$ in $\mathrm{Et}_{2} \mathrm{O}(5 \mathrm{~mL})$ to a suspension of $\mathrm{LiAlH}_{4}(310 \mathrm{mg}, 8.2 \mathrm{mmol})$ in $\mathrm{Et}_{2} \mathrm{O}(7.5 \mathrm{~mL})$ at $0{ }^{\circ} \mathrm{C}$, stirring of the mixture for $15 \mathrm{~min}$ and decantation of the residual solid]. The resulting mixture was stirred for $30 \mathrm{~min}$ and hydrolysed with a 5 $\mathrm{N}$ aqueous solution of ammonia $(10 \mathrm{~mL})$. The aqueous layer was separated and extracted with AcOEt $(3 \times 10 \mathrm{~mL})$. The combined organic layers were washed with water $(10 \mathrm{~mL})$, dried $\left(\mathrm{MgSO}_{4}\right)$, filtered through a pad of celite and concentrated in vacuo. The residue was purified by flash chromatography (neutral $\mathrm{Al}_{2} \mathrm{O}_{3}, \mathrm{CH}_{2} \mathrm{Cl}_{2}$ ) to give enaminonitrile 7 as a beige solid (177 mg, $75 \%$ ): $\mathrm{mp}$ 192-193 ${ }^{\circ} \mathrm{C}$; IR (neat) $2168 \mathrm{~cm}^{-1} ;{ }^{1} \mathrm{H}$ NMR (200 MHz, $\left.\mathrm{CDCl}_{3}\right) \delta 1.92-1.99(\mathrm{~m}, 2 \mathrm{H}), 2.80-2.82(\mathrm{~m}, 2 \mathrm{H}), 3.05(\mathrm{t}, J=7.8$ $\mathrm{Hz}, 2 \mathrm{H}), 3.45-3.49(\mathrm{~m}, 4 \mathrm{H}), 5.82(\mathrm{~s}, 2 \mathrm{H}), 6.41(\mathrm{~s}, 1 \mathrm{H}), 6.95(\mathrm{~s}, 1 \mathrm{H}) ;{ }^{13} \mathrm{C} \mathrm{NMR}\left(50 \mathrm{MHz}, \mathrm{CDCl}_{3}\right) \delta 21.1$ $\left(\mathrm{CH}_{2}\right), 35.6\left(\mathrm{CH}_{2}\right), 36.5\left(\mathrm{CH}_{2}\right), 51.8\left(\mathrm{CH}_{2}\right), 58.2\left(\mathrm{CH}_{2}\right), 74.0(\mathrm{C}), 100.9\left(\mathrm{CH}_{2}\right), 106.7(\mathrm{CH}), 109.1(\mathrm{CH})$, 123.6 (C), 127.9 (C), 130.2 (C), 144.7 (C), 146.7 (C), 157.4 (C).

\section{2,3,5,6,2',3',5',6'-Octahydro-1H,1'H-[1,1']bis[benzo[d]pyrrolo[1,2-a]azepinyl]-11,11'-}

dicarbonitrile (8). To a solution of 1-lithio-1-ethoxyethene (2.23 $\mathrm{mmol})$ [prepared as above] was added 
dropwise a solution of nitrile $7(57 \mathrm{mg}, 0.224 \mathrm{mmol})$ in THF $(5 \mathrm{~mL})$. The mixture was stirred at $-78^{\circ} \mathrm{C}$ for $15 \mathrm{~min}$, stirred $3 \mathrm{~h}$ at $0{ }^{\circ} \mathrm{C}$, and hydrolysed with a saturated aqueous solution of $\mathrm{NH}_{4} \mathrm{Cl}(1 \mathrm{~mL})$. The aqueous layer was separated and extracted with $\mathrm{CH}_{2} \mathrm{Cl}_{2}(2 \times 10 \mathrm{~mL})$. The combined organic layers were washed with brine $(5 \mathrm{~mL})$, dried $\left(\mathrm{Na}_{2} \mathrm{CO}_{3}\right)$ and concentrated in vacuo. The residue was purified by flash chromatography $\left(\mathrm{SiO}_{2}, 1: 0\right.$ to $4: 1 \mathrm{CH}_{2} \mathrm{Cl}_{2} / \mathrm{AcOEt}$, ) to give dimer 8 (10 $\left.\mathrm{mg}, 18 \%\right)$ as a beige amorphous solid; IR (neat) $2182 \mathrm{~cm}^{-1} ;{ }^{1} \mathrm{H}$ NMR (400 MHz, $\left.\mathrm{CDCl}_{3}\right) \delta 1.80(\mathrm{dd}, J=12.4,5.3 \mathrm{~Hz}, 1 \mathrm{H}), 2.32$ (dddd, $J$ $=12.4,10.5,8.5,4.5 \mathrm{~Hz}, 1 \mathrm{H}), 2.75(\mathrm{dd}, J=14.5,5.5 \mathrm{~Hz}, 1 \mathrm{H}), 3.12(\mathrm{ddd}, J=14.5,10.1,1.2 \mathrm{~Hz}, 1 \mathrm{H})$, $3.29(\mathrm{dd}, J=9.6,6.7 \mathrm{~Hz}, 1 \mathrm{H}), 3.39(\mathrm{dd}, J=10.5,8.5 \mathrm{~Hz}, 1 \mathrm{H}), 3.60(\mathrm{t}, J=10.1 \mathrm{~Hz}, 1 \mathrm{H}), 3.75(\mathrm{ddd}, J=$ 11.0, 6.0, $1.0 \mathrm{~Hz}, 1 \mathrm{H}), 4.00(\mathrm{dt}, J=10.5,5.3 \mathrm{~Hz}, 1 \mathrm{H}), 5.86(\mathrm{br} \mathrm{s}, 2 \mathrm{H}), 6.46(\mathrm{~s}, 1 \mathrm{H}), 6.89(\mathrm{~s}, 1 \mathrm{H}) ;{ }^{13} \mathrm{C}$ NMR (100 MHz, $\left.\mathrm{CDCl}_{3}\right) \delta 30.1\left(\mathrm{CH}_{2}\right), 34.6\left(\mathrm{CH}_{2}\right), 51.2(\mathrm{CH}), 53.2\left(\mathrm{CH}_{2}\right), 54.5\left(\mathrm{CH}_{2}\right), 96.1(\mathrm{C}), 100.9$ $\left(\mathrm{CH}_{2}\right), 106.7(\mathrm{CH}), 109.4(\mathrm{CH}), 123.9(\mathrm{C}), 127.7$ (C), $131.3(\mathrm{C}), 145.1(\mathrm{C}), 146.5(\mathrm{C}), 159.0(\mathrm{C})$; ESI$\mathrm{MS}(+20 \mathrm{~V})\left(\mathrm{MeOH}+\mathrm{HCOONH}_{4}\right) m / z\left(\%\right.$ rel intensity) $524.2(39)\left[\mathrm{M}+\mathrm{NH}_{4}\right]^{+}, 507.2(100)[\mathrm{M}+\mathrm{H}]^{+}$, 450.1 (10), 396.3 (14), 367.2 (39).

\section{8-Ethoxy-9-hydroxy-2,3,5,6-tetrahydro-1H-benzo[d]pyrrolo[1,2-a]azepine-11-carbonitrile}

and 9-Ethoxy-8-hydroxy-2,3,5,6-tetrahydro-1H-benzo[d]pyrrolo[1,2-a]azepine-11-carbonitrile

(10). To a solution of $7(290 \mathrm{mg}, 1.14 \mathrm{mmol})$ in toluene $(50 \mathrm{~mL})$ was added methylmagnesium bromide (19 $\mathrm{mL}$ of a $3 \mathrm{M}$ solution in $\mathrm{Et}_{2} \mathrm{O}, 57 \mathrm{mmol}$ ). $\mathrm{Et}_{2} \mathrm{O}$ was distilled, the mixture was refluxed for $5 \mathrm{~h}$ and poured into a saturated aqueous solution of $\mathrm{NH}_{4} \mathrm{Cl}$. The aqueous layer was extracted with AcOEt $(4 \times 50$ $\mathrm{mL})$. The combined organic extracts were dried $\left(\mathrm{MgSO}_{4}\right)$ and concentrated in vacuo, delivering in $70 \%$ combined yield $(215 \mathrm{mg})$ a mixture of regioisomers 9 and $\mathbf{1 0}$ in the respective ratio of 2.4:1, determined by HPLC analysis of the crude (Spherisorb S 5W, $25 \mathrm{~cm}$ length, $4.9 \mathrm{~mm}$ internal diameter ; detection : UV at $254 \mathrm{~nm}$; eluent : 50\% AcOEt in cyclohexane; flow rate : $1 \mathrm{~mL}$ per min). 9 and $\mathbf{1 0}$ were separated by flash chromatography $\left(\mathrm{SiO}_{2}, 9: 6: 1\right.$ cyclohexane/AcOEt/AcOH, ; $\left.9: R_{\mathrm{f}} 0.23,10: R_{\mathrm{f}} 0.31\right)$.

Major isomer (9): colorless solid; mp 187-188 ${ }^{\circ} \mathrm{C}$; Analytical HPLC : homogeneous single peak, $t_{\mathrm{R}}=$ $13.22 \mathrm{~min} ; \mathrm{UV} \lambda_{\max }\left(\mathrm{CHCl}_{3}\right) 241 \mathrm{~nm}$ ( $\left.\varepsilon 16000\right), 318 \mathrm{~nm}$ ( 1616000$)$; IR (neat) 3226, 2177 $\mathrm{cm}^{-1} ;{ }^{1} \mathrm{H}$ NMR $\left(400 \mathrm{MHz}, \mathrm{CDCl}_{3}\right) \delta 1.43(\mathrm{t}, \mathrm{J}=7.0 \mathrm{~Hz}, 3 \mathrm{H}), 2.00-2.08(\mathrm{~m}, 2 \mathrm{H}), 2.90-2.92(\mathrm{~m}, 2 \mathrm{H}), 3.13(\mathrm{t}, \mathrm{J}=7.8 \mathrm{~Hz}$, 2H), 3.54-3.58 (m, 4H), 4.07 (q, J = 7.0 Hz, 2H), $5.55(\mathrm{~s}, 1 \mathrm{H}), 6.50(\mathrm{~s}, 1 \mathrm{H}), 7.13(\mathrm{~s}, 1 \mathrm{H}) ;{ }^{13} \mathrm{C}$ NMR $(100$ $\left.\mathrm{MHz}, \mathrm{CDCl}_{3}\right) \delta 14.9\left(\mathrm{CH}_{3}\right), 21.1\left(\mathrm{CH}_{2}\right), 35.6\left(\mathrm{CH}_{2}\right), 36.6\left(\mathrm{CH}_{2}\right), 51.5\left(\mathrm{CH}_{2}\right), 58.2\left(\mathrm{CH}_{2}\right), 64.8\left(\mathrm{CH}_{2}\right)$, $74.0(\mathrm{C}), 112.7(\mathrm{CH}), 113.0(\mathrm{CH}), 123.5$ (C), 127.4 (C), 128.5 (C), 142.9 (C), 144.7 (C), 157.5 (C); EIMS (8.4 V, $\left.400{ }^{\circ} \mathrm{C}\right) \mathrm{m} / \mathrm{z}$ (\% rel intensity) 269.9 (47) $[\mathrm{M}]^{+}, 240.9$ (100), 212.9 (33); HRMS for $\mathrm{C}_{16} \mathrm{H}_{18} \mathrm{O}_{2} \mathrm{~N}_{2}$ calcd. 270.1368, found 270.1375; Anal. for $\mathrm{C}_{16} \mathrm{H}_{18} \mathrm{~N}_{2} \mathrm{O}_{2}$, calcd. C, 71.09; H, 6.71; N, 10.36, found C, 70.85; H, 6.78; N, 10.36 .

Minor isomer (10): colorless solid; $\mathrm{mp} 225-226{ }^{\circ} \mathrm{C}$; Analytical HPLC : homogeneous single peak, $t_{\mathrm{R}}=$ $9.79 \mathrm{~min} ; \mathrm{UV} \lambda_{\max }\left(\mathrm{CHCl}_{3}\right) 241 \mathrm{~nm}(\varepsilon 15800), 317 \mathrm{~nm}(\varepsilon 12600)$; IR (neat) 3372, $2167 \mathrm{~cm}^{-1}$; ${ }^{1} \mathrm{H}$ NMR 
$\left(400 \mathrm{MHz}, \mathrm{CDCl}_{3}\right) \delta 1.44(\mathrm{t}, \mathrm{J}=7.0 \mathrm{~Hz}, 3 \mathrm{H}), 2.01-2.09(\mathrm{~m}, 2 \mathrm{H}), 2.90(\mathrm{t}, \mathrm{J}=4.5 \mathrm{~Hz}, 2 \mathrm{H}), 3.14(\mathrm{t}, \mathrm{J}=$ $7.8 \mathrm{~Hz}, 2 \mathrm{H}), 3.54-3.58(\mathrm{~m}, 4 \mathrm{H}), 4.14(\mathrm{q}, \mathrm{J}=7.0 \mathrm{~Hz}, 2 \mathrm{H}), 5.52(\mathrm{~s}, 1 \mathrm{H}), 6.61(\mathrm{~s}, 1 \mathrm{H}), 7.03(\mathrm{~s}, 1 \mathrm{H}) ;{ }^{13} \mathrm{C}$ NMR $\left(100 \mathrm{MHz}, \mathrm{CDCl}_{3}\right) \delta 14.8\left(\mathrm{CH}_{3}\right), 21.2\left(\mathrm{CH}_{2}\right), 35.3\left(\mathrm{CH}_{2}\right), 36.6\left(\mathrm{CH}_{2}\right), 51.5\left(\mathrm{CH}_{2}\right), 58.2\left(\mathrm{CH}_{2}\right)$, $64.7\left(\mathrm{CH}_{2}\right), 74.0(\mathrm{C}), 110.1(\mathrm{CH}), 115.2(\mathrm{CH}), 123.9(\mathrm{C}), 125.9(\mathrm{C}), 129.8(\mathrm{C}), 142.8(\mathrm{C}), 144.6(\mathrm{C})$, 157.3 (C); EI-MS (7.2 V, $\left.300{ }^{\circ} \mathrm{C}\right) \mathrm{m} / z$ (\% rel intensity) 270.3 (100) [M] ${ }^{+}, 254.2$ (14), 241.2 (47), 213.2 (23); HRMS for $\mathrm{C}_{16} \mathrm{H}_{18} \mathrm{O}_{2} \mathrm{~N}_{2}$ calcd. 270.1368, found 270.1378 .

X-ray Data Collection and Processing. For 2, the crystallization was performed in a THF solution. A light pink crystal sample $\left(0.55 \times 0.50 \times 0.40 \mathrm{~mm}^{3}\right)$ was used for the crystallographic study carried out on a Bruker-Smart CCD diffractometer at 100.0(1) K obtained by a $\mathrm{N}_{2}$ gas stream produced by the Oxford Cryosystem device. The CCD area detector was placed at $4 \mathrm{~cm}$ from the crystal sample. The experiment was performed using the graphite monochromated MoKa X-ray radiation $(\lambda=0.71073 \AA)$. The diffracted intensity profiles were recorded as $\omega$-scans (rotation angle intervals $\Delta \omega=0.15^{\circ}$ ) in the Bragg angle range $\theta=2.45-33.66^{\circ}\left((\sin \theta / \lambda)_{\max }=0.78 \AA^{-1}\right)$ corresponding to a minimum resolution of $d=0.64$ Å. Yellow-brown crystal samples for crystallographic studies of 7 were obtained from slow evaporation of a saturated dichloromethane solution. A suitable large crystal specimen of dimension $0.65 \times 0.54 \mathrm{x}$ $0.50 \mathrm{~mm}^{3}$ was chosen for the high-resolution diffraction experiment in the same conditions as above. In this case, however, the data range was extended to $\theta=52.10^{\circ}$ corresponding to $(\sin \theta / \lambda)_{\max }=1.11 \AA^{-1}$ or a resolution $d=0.45 \AA$. For the sake of the measurement accuracy, a total number of 161121 data were collected for 7 in order to maximize the redundancy of the equivalent measurements in the complete sphere of diffraction. For the two compounds, the Lorentz-polarization correction and the integration of the intensity profiles were performed with the Bruker SAINT software package. ${ }^{69}$ The final cell parameter values reported in Table 1 were estimated during the integration processing of the full data set. SADABS program ${ }^{69}$ was used for the empirical absorption correction, the rescaling of equivalent and redundant reflection intensities $I$ and for a better estimate of the standard uncertainties $\sigma(I)$. The sorting and averaging (in -1 point group for 2 and in $2 / \mathrm{m}$ point group for 7 ) of the data were obtained using the $\operatorname{SORTAV}^{70}$ program. Table 1 summarizes the X-ray diffraction results of these two experiments. 
Acknowledgment. This paper is dedicated to Professor Gilbert Stork on the occasion of his 82th birthday. This work was supported by the Centre National de la Recherche Scientifique (CNRS), the Ministère de l'Education Nationale, de la Recherche et de la Technologie and the Ecole Centrale Paris. M.P. is grateful for the fellowship funding from CNRS and Oncopharm SA (France). G. B. is grateful for the associated assistant position for two months at the Ecole Centrale Paris.

Supporting Information Available: ${ }^{1} \mathrm{H}$ and ${ }^{13} \mathrm{C}$ NMR spectra of all compounds described herein. Crystallographic tables of atomic coordinates and thermal displacements of $\mathbf{2}$ and $\mathbf{7}$ and multipole parameters and local atomic frames of 7 (PDF). This material is available free of charge via the Internet at htpp://pubs.acs.org.

\section{References}

(1) (a) Paudler, W. W.; Kerley, G. I.; McKay, J. J. Org. Chem. 1963, 28, 2194-2197. (b) For a recent review, see: Cephalotaxus alkaloids: Miah, M. A. J., Hudlicky, T., Reed, J.W. In The Alkaloids; Cordell, G. A., Ed., Academic: San Diego, 1998, Vol. 51, pp. 199-269.

(2) (a) Cephalotaxus spp. In Chinese Drugs of Plant Origin, Chemistry, Pharmacology, and Use in Traditional and Modern Medicine; Tang, W., Eisenbrand; G., Eds., Springer: Berlin, 1992, pp. 281-306. (b) Powell, R. G.; Weisleder, D.; Smith, Jr., C. R. J. Pharm. Sci. 1972, 61, 1227-1230. (c) Zhou, D.-C.; Zittoun, R.; Marie, J.-P. Bull. Cancer 1995, 82, 987-995. (d) Zhou, D.-C.; Ramond, S.; Viguie, F.; Faussat, A.-M.; Zittoun, R.; Marie, J.-P. Int. J. Cancer 1996, 65, 365371. (e) For an enantioselective synthesis of the ester side chain of homoharringtonine, see : Keller, L.; Dumas, F.; d'Angelo, J. Eur. J. Org. Chem. 2003, 2488-2497.

(3) Total syntheses of cephalotaxine: (a) Li, W.-D. Z.; Wang, Y.-Q. Org. Lett. 2003, 5, 2931-2934. (b) Suga, S.; Watanabe, M.; Yoshida, J-i. J. Am. Chem. Soc. 2002, 124, 14824-14825, and references cited therein. (c) Koseki, Y.; Sato, H.; Watanabe, Y.; Nagasaka, T. Org. Lett. 2002, 4, 885-888.

(4) de Oliveira, E. R.; Dumas, F.; d'Angelo, J. Tetrahedron Lett. 1997, 38, 3723-3726.

(5) Erian, A. W. Chem. Rev. 1993, 93, 6,1991-2005.

(6) Katsuyama, I.; Ogawa, S.; Nakamura, H.; Yamaguchi, Y.; Funabiki, K.; Matsui, M.; Muramatsu, H.; Shibata, K. Heterocycles 1998, 48, 779-785.

(7) Nemes, P.; Balázs, B.; Tóth, G.; Scheiber, P. Synlett 2000, 1327-1329. 
(8) Fleming, F. F.; Hussain, Z.; Weaver, D.; Norman, R. E. J. Org. Chem. 1997, 62, 1305-1309.

(9) Breneman, C. M.; Moore, J. A. Struct. Chem. 1997, 8, 13-19.

(10) Hansen, N. K.; Coppens, P. Acta Crystallogr. 1978, A34, 909-921.

(11) Clementi, E.; Roetti, C. In Atomic data and Nuclear data tables; Academic: New York, 1974, Vol. 14, pp. 177-178.

(12) Clementi, E. ; Raimondi, D. L. J. Chem. Phys. 1963, 41, 2686-2689.

(13) ELECTROS, STATDENS, FIELD+: Computer programs to calculate electrostatic properties from high resolution X-ray diffraction: Ghermani, N. E.; Bouhmaida, N.; Lecomte, C. Internal report UMR CNRS 7036, Université Henri Poincaré, Nancy 1, France ; UMR CNRS 8612, Université Paris XI, France and Université Cadi Ayyad, Morocco, 1992-2002.

(14) Farrugia, L. J. J. Appl. Crystallogr. 1999, 32, 837-838.

(15) Sheldrick, G. M. SHELXL97 and SHELXS97: Program for the Refinement of Crystal Structures; University of Göttingen: Göttingen, Germany, 1997.

(16) Cruickshank, D. W. J. Acta Crystallogr. 1949, 2, 65-82.

(17) Rees, B. Acta Crystallogr. 1976, A32, 483-488.

(18) ORTEP-III report ORNL-6895: Burnett, M. N.; Johnson, C. K. Oak Ridge International Laboratory, Tennessee, USA, 1996.

(19) Coppens, P.; Guru Row, T. N.; Leung, P.; Stevens, E. D.; Becker, P. J.; Yang, Y. W. Acta Crystallogr. 1979, A35, 63-72.

(20) Atoms-in-Molecules: A Quantum Theory; Bader, R. F. W., Clarendon: Oxford, 1990.

(21) Atomic Properties from Experimental Electron Densities: Program Newprop-Int: Souhassou, M. $19^{\text {th }}$ European Crystallographic Meeting, Nancy, France, August 25-31 2000, Abstract N ${ }^{\circ}$ S2m2-p2, P. 195 (also LCM3B Internal Report, Université Henri Poincaré, Nancy 1, France).

(22) MOLEKEL: An Interactive Molecular Graphics Tool: Portmann, S.; Lüthi, H. P. Chimia 2000, 54, 766-770.

(23) Abraham, D. J.; Rosenstein, R. D.; McGandy, E. L. Tetrahedron Lett. 1969, 4085 - 4086.

(24) Semmelhack, M. F.; Chong, B. P.; Stauffer, R. D.; Rogerson, T. D.; Chong, A.; Jones, L. D. J. Am. Chem. Soc. 1975, 97, 2507-2516.

(25) (a) Eisch, J. J.; Jacobs, A. M. J. Org. Chem. 1963, 2145-2146. (b) Fleming, F. F.; Wang, Q. Chem. Rev. 2003, 103, 2035-2077.

(26) (a) Corey, E. J.; Boaz, N. W. Tetrahedron Lett. 1985, 26, 6019-6022. (b) Alexakis, A.; Berlan, J.; Besace, Y. Tetrahedron Lett. 1986, 27, 1047-1050. (c) Yamamoto, Y.; Maruyama, K. J. Am. Chem. Soc. 1978, 100, 3240-3241. (d) Lipshutz, B. H.; Parker, D. A.; Kozlowski, J. A.; Nguyen, S. L. Tetrahedron Lett. 1984, 25, 5959-5962. (e) Synthetic Procedures Involving Organocopper 
Reagents: Lipshutz, B. H. In Organometallics in Synthesis ; Schlosser, M., Ed.; Wiley: New York, 1994, pp 283-382.

(27) Baldwin, J. E.; Höfle, G. A.; Lever, Jr., O. W. J. Am. Chem. Soc. 1974, 96, 7125-7127.

(28) Kim, S.-H.; Cha, J. K. Synthesis 2000, 14, 2113-2116.

(29) Jenn, T.; Heissler, D. Tetrahedron 1998, 54, 107-118.

(30) Tokoroyama, T.; Tsukamoto, M.; Asada, T.; Iio, H. Tetrahedron Lett. 1987, 28, 6645-6648.

(31) Cha, J. S.; Chang, S. W.; Kwon, O. O.; Kim, J. M. Synlett 1996, 165-166.

(32) Brown, H. C.; Choi, Y. M.; Narasimhan, S. J. Org. Chem. 1982, 47, 3153-3163.

(33) Jousse-Karinthi, C.; Riche, C.; Chiaroni, A.; Desmaële, D. Eur. J. Org. Chem. 2001, 3631-3640.

(34) (a) Keller, L.; Dumas, F.; Pizzonero, M.; d'Angelo, J.; Morgant, G.; Nguyen-Huy, D.; Tetrahedron Lett. 2002, 43, 3225 - 3228. (b) Majetich, G.; Casares, A. M.; Chapman, D.; Behnke, M. Tetrahedron Lett. 1983, 24, 1909-1912.

(35) (a) Friesen, R. W. J. Chem. Soc., Perkin Trans. 1, 2001, 1969-2001. (b) Angelastro, M. R.; Peet, N. P.; Bey, P. J. Org. Chem. 1989, 54, 3913-3916.

(36) Braish, T. F.; Saddler, J. C.; Fuchs, P. L. J. Org. Chem. 1988, 53, 3647-3658.

(37) (a) Brown, H.C.; Krishnamurthy, S., Tetrahedron, 1979, 35, 567-607. (b) Brown, H. C.; Garg, C. P. J. Am. Chem. Soc. 1964, 86, 1085-1089.

(38) Degani, I.; Fochi, R. Synthesis 1976, 757-759.

(39) Fry, J. L.; Ott, R. A. J. Org. Chem. 1981, 46, 602-607.

(40) Orlemans, E. O. M.; Verboom, W.; Scheltinga, M. W.; Reinhoudt, D. N.; Lelieveld, P.; Fiebig, H. H.; Winterhalter, B. R.; Double, J. A.; Bibby, M. C. J. Med. Chem. 1989, 32, 1612-1620.

(41) (a) Toyota, S.; Nakagawa, T.; Kotani, M.; Ōki, M.; Uekusa, H.; Ohashi, Y. Tetrahedron 2002, 58, 10345-10351. (b) Kurteva, V.; Simova, S. Eur. J. Med. Chem. 2003, 38, 219-222.

(42) Villar, H.; Guibé, F.; Aroulanda, C.; Lesot, P. Tetrahedron: Asymmetry 2002, 13, 1465-1475.

(43) Cabiddu, S; Secci, M.; Maccioni, A. J. Organometal. Chem. 1975, 88, 121-128.

(44) X-ray Charge Densities and Chemical Bonding; Coppens, P. International Union of Crystallography: Oxford University, 1997.

(45) Bader, R. F. W.; Carroll, M. T.; Cheeseman, J. R.; Chang, C. J. Am. Chem. Soc. 1987, 109, 7968-7979.

(46) Politzer, P.; Murray, J. S. Fluid Phase Equilibria 2001, 185, 129-137.

(47) Spasojević-de Biré, A.; Bouhmaida, N.; Kremenović, A.; Morgant, G.; Ghermani, N. E. J. Phys. Chem. A 2002, 106, 12170-12177.

(48) Bouhmaida, N.; Dutheil, M.; Ghermani, N. E.; Becker, P. J. Chem. Phys. 2002, 116, 14, 61966204. 
(49) Kuehne, M. E.; Bornmann, W. G.; Parsons, W. H.; Spitzer, T. D.; Blount, J. F.; Zubieta, J. J. Org. Chem. 1988, 53, 3439-3450.

(50) Müller, G.; Lutz, M.; Harder, S. Acta Crystallogr. 1996, B52, 1014-1022.

(51) Allen, F. H. Acta Crystallogr., 2002, B58, 380-388.

(52) Spasojevic-de Biré A.; Nguyen Q. D.; Hansen N. K.; Fischer E. O. Inorg. Chem. 1993, 32, 5354-5361.

(53) Zhong, S.; Deng, Y.; Yu, K.; Zhu, J.; Mi, A.; Jiang, Y.; Zhang, G. Acta Crystallogr. 1999, C55, IUC9900013.

(54) Fang, F. G.; Maier, M. E.; Danishefsky, S. J. J. Org. Chem. 1990, 55, 831-838.

(55) Brown, K. L.; Damm, L.; Dunitz, J. D.; Eschenmoser, A.; Hobi, R.; Kratky, C. Helv. Chim. Acta 1978, 61, 3108-3135.

(56) Arora, S. K.; Bates, R. B.; Grady, R. A.; Germain, G.; Declercq, J. P.; Powell, R. G. J. Org. Chem. 1976, 41, 551-554.

(57) Laane, J.; Bondoc, E.; Sakurai, S.; Morris, K.; Meinander, N.; Choo, J. J. Am. Chem. Soc. 2000, 122, 2628-2634.

(58) Choo, J. J. Mol. Struct. 2001, 597, 235-240.

(59) Moon, S.; Kwon, Y.; Lee, J.; Choo, J. J. Phys. Chem. A 2001, 105, 3221-3225.

(60) Lopez, J. L.; Mandado, M.; Grana, A. M.; Mosquera, R. A. Int. J. Quantum Chem. 2002, 86, 190-198.

(61) Janczak, J.; Kubiak, R. J. Mol. Struct. 2000, 553, 157-166.

(62) Tang, T. H.; Fu, X. Y. J. Mol. Struct. (Theochem) 1997, 392, 153-167.

(63) Kozísek, J.; Hansen, N. K.; Fuess, H. Acta Crystallogr. 2002, B58, 463-470.

(64) Boyd, R. J.; Jones, W. E.; Ling, K. W. Chem. Phys. 1981, 58, 203-210.

(65) Platts, J., A.; Howard, S., T.; Fallis, I. A. Chem. Phys. Lett. 1998, 285, 198-204.

(66) Alcolea Palafox, M.; Rastogi, V., K.; Chatar S.; Tanwar, V. K. Spectrochim. Acta A 2001, 57, 2373-2389.

(67) Zernera, M., C.; Reidlingerb, C.; Fabian, W., M., F.; Junek, H. J. Mol. Struct. (Theochem) 2001, $543,129-146$.

(68) Auerbach, J.; Weinreb, S. M. J. Am. Chem. Soc. 1972, 94, 7172-7173.

(69) ASTRO (5.007), SAINT (5.007) and SADABS (5.007): Data Collection and Processing Software for the SMART System (5.054). Siemens (BRUKER-AXS). Analytical X-ray Instruments Inc. Madison, Wisconsin, USA, 1998.

(70) Blessing, R. H. J. Appl. Crystallogr. 1997, 30, 421-426. 


\section{Crystallographic/Experimental Electron Density Characterizations and Reactions with Nucleophiles of $\beta$-Enaminonitriles Possessing a Pyrrolobenzazepine Core}

Mathieu Pizzonero ${ }^{\S}$, Laurent Keller ${ }^{\S}$, Françoise Dumas ${ }^{\S}$, Michèle Ourevitch ${ }^{\S}$, Georges Morgant ${ }^{\S}$, Anne Spasojević-de Biré ${ }^{\ddagger}$ Goran Bogdanović ${ }^{\ddagger}$, , Nour Eddine Ghermani ${ }^{\dagger \neq},{ }^{*}$ and Jean d’Angelo ${ }^{\S^{*}}$

TOC Graphic
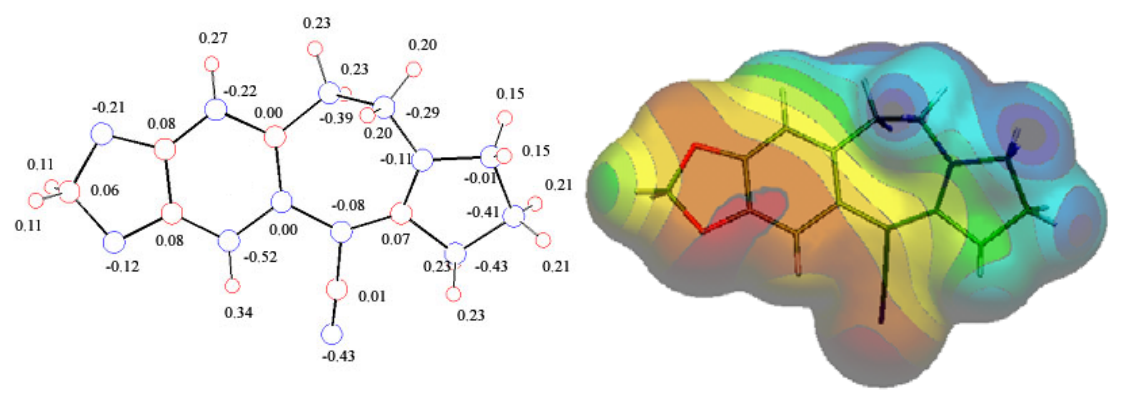

Atomic net charges

Surface electrostatic potential 